\author{
Revista Venezolana de Gerencia (RVG) \\ Año 8. № 22, 2003, 181-216 \\ Universidad del Zulia (LUZ) • ISSN 1315-9984
}

\title{
Globalización y gestión de los riesgos del trabajo en el MERCOSUR*
}

\author{
Silva, María Alejandra**
}

\section{Resumen}

El trabajo tiene como objeto realizar un estudio de la gestión de los riesgos en empresas donde se presume que los trabajadores exponen más su vida y su salud. En este caso el área investigada es la de empresas de la construcción radicadas en ciudades del MERCOSUR: Argentina, Brasil, Pa raguay y Uruguay. Se analizó cada sistema de cobertura de los riesgos del trabajo y se determinó los modos de gestión que poseen las empresas de dichas ciudades en cuanto a los riesgos en la obra, en el marco de los nuevos elementos jurídicos de la globalización de la producción. Esta investigación se hizo a través del uso de los aportes bibliográficos, la técnica de observación directa en las obras, las entrevistas a informantes calificados y las encuestas semi-estructuradas a los trabajadores. Los resultados alertan sobre un crecimiento de la población que carece de cobertura de los riesgos del trabajo, que afecta principalmente a la Argentina y Paraguay, pero a su vez, constituyen retos fundamentales para la gestión preventiva de los riesgos en todas las instancias de una obra: idea, proyecto, ejecución y post-obra como se intenta en algunos sitios de Brasil. Concluyéndose que se hace ne cesario retomar y profundizar la noción de salud globalizada a fin de evitar la exportación de los riesgos que perjudica a quienes poseen la legislación y los sistemas políticos y administrativo débiles. Además se debe tender a la sustitución del paradigma "expost" que considera a los accidentes y las enfermedades a partir de las consecuencias o secuelas perjudiciales; por el enfoque preventivo; "ex-ante"; que vincula a tal dolencia o a tal evento nocivo con el conjunto de condiciones de trabajo, consideradas globalmente, con la finalidad de que se tomen todos los recaudos para evitar que se afecte la salud física, mental o social del trabajador.

Palabras clave: Globalización, MERCOSUR, gestión de la construcción, higiene y seguridad, cobertura de riesgos del trabajo.

Recibido: 02-01-28 . Aceptado: 03-02-06

* Una primera versión del documento se presentó en el XXIII Congreso de la Asociación Latinoamericana de Sociología organizado por la Asociación Latinoamericana de Sociología en la Universidad de San Carlos, Guatemala, del 29 de octubre al 2 de noviembre de 2001.

** Licenciada en Ciencia Política y trabaja como Profesora en la Universidad Nacional de Rosario, Argentina. Es Magister en Sociología/FLACSO. El presente trabajo es un avance de la investigación financiada por el Consejo Nacional de Investigaciones Científicas y Técnicas (CONICET). Ayacucho 1408, 6 to "B". 2.000. Rosario, República Argentina.

E-mail: msilvafmedic.unr.edu.ar 


\section{Globalization and Labor Risk Management in MERCOSUR}

\section{Abstract}

The objective of this paper is to review a study on the management of risk in firms where there is a high level of worker risk in relation to life and health. In this case the area researched is construction firms located in cities in the MERCOSUR region: Argentina, Brazil, Paraguay, and Uruguay. Each system of risk coverage is analyzed and management modes are determined for companies in these cities in relation to labor risks within the framework of new judicial elements related to the globalization of production. This paper is based on bibliographical support, direct observation at work sites, and interviews with qualified informants using semi-structured questionnaires with workers. The results alert us to the growing population of workers who are not covered for work risks principally in Argentina and Paraguay. At the same time this constitutes fundamental challenges to management in the prevention of risks in all phases of a project: the idea, the project, the execution, and the post-operational phase as has been attempted in certain sites in Brazil. The conclusion is that it is necessary to study and deepen the notion of globalized health in order to avoid the exportation of the risks that prejudice those who are under weaker legal, political and administrative systems. Also it is necessary to substitute the "expost" paradigm that considers accidents, and illnesses as part of the consequences or lasting negative effects, and substitute it with the preventative "ex-ante" focus that links illnesses and negative events with the totality of work conditions considered globally, for the purpose of including all incidents and aspects to avoid negative physical, mental or social affects on the worker.

Key words: Globalization, MERCOSUR, construction management, hygiene and safety, labor risk coverage.

El proceso de producción en la construcción, a diferencia de otros procesos industriales, ha sido caracterizado reiteradamente como "industria de planta móvil. Esta caracterización implica considerar una serie de aspectos diferenciales. Por ejemplo interesa tener en cuenta esta diferencia en relación a la forma de inversión. Mientras que en otros procesos industriales es necesaria una primera gran inversión en infraestructura.

\section{Introducción}

El trabajo tiene como objeto realizar un estudio de la gestión de los riesgos en empresas donde se presume que los trabajadores exponen más su vida y su salud. En este caso el área investigada es la de empresas de la construcción radicadas en ciudades del MERCOSUR: Argentina, Brasil, Paraguay y Uruguay.

El proceso de producción en la construcción a diferencia de otros procesos industriales, ha sido caracterizado reiteradamente como industria de planta móvíl. Esta caracaterización implica considerar una serie de aspectos diferenciales por ejemplo, interesa tener en cuenta esta diferencia en relación a la forma de inversión. Mientras que en otros procesos industriales es necesaria una primera gran 
inversión en infraestructura, en la construcción la inversión es variable y no continua, dependiendo de la realización de las obras. Este aspecto fundamentalmente económico, va acompañado de otros que tienen que ver con la organización empresarial" (Prat, 2000:5), como la convocatoria para la ejecución a un nú mero variable de empresas subcontratadas.

Además, la industria de la construcción produce siempre en un sitio distinto, está condicionada por razones climáticas y territoriales, sujeta a un proyecto diferente con un determinado grado de flexibilidad, margen de libertad y conformado por cuadrillas disímiles.

Cabe aclarar que los pasos previstos para la realización de una obra incluyen la idea, el anteproyecto, el proyecto y la ejecución Si bien la concepción, el diseño de la obra, está diferenciado por equipo de profesionales y técnicos, mientras que la ejecución la conforma otro equipo con gran autonomía: "a nivel de la ejecución, el fenómeno más señalable es la gran autonomía de la dirección de obra y del jefe de obra... El director de obra es generalmente responsable de las relaciones obra-empresa, de la gestión financiera y de la organización general de la obra, del seguimiento de la planificación, la cual ha sido establecida con la dirección. El jefe de obra es a menudo responsable de la organización del trabajo, del reclutamiento y del despido de la mano de obra, de la atribución de salarios y, por tanto, de la clasificación, de la constitución de equipos y de su afectación en el desarrollo del trabajo" (Campinos-Dubernet, 1984:83).

Sin embargo, por debajo de este nivel de control de la ejecución, difícilmente pueden caracterizarse puestos de trabajo, porque: "la lógica del conjunto del trabajo en obra, las sucesiones, las simultaneidades, las interdependencias, obstaculizan una normalización individual y demasiado estricta en el sentido taylorista clásico en que estas normas se han aplicado en la industria de serie" (Coriat, 1984:93).

"El trabajo en la obra se vuelve más complejo porque entre la idea y la realización de un proyecto existen numerosos riesgos a saber: materiales (toxicidad y fragilidad); útiles (complejidad de empleo y estabilidad); de energía (presión y falta de visibilidad); con los trabajadores (preparación para el trabajo y adaptabilidad al puesto), y con respecto al modo de operar" (AISS, 1986:10). Si bien esos riesgos a la salud no pueden eliminarse, pueden llegar a disminuir mediante el conocimiento de los mismos por todos los participantes en el proyecto, la organización y la ejecución.

En ese marco se abordan los disímiles criterios regionales acerca del tratamiento que recibe la salud de los trabajadores en cada país, a partir del análisis de la cobertura de los riesgos del trabajo, la legislación de higiene y seguridad y la forma de gestionar los riesgos en cada fase de la obra. Además, se analizan los aspectos relevantes de las negociaciones alcanzadas en el Subgrupo 10 y 11, así como los debates existentes en cada país desde la mirada de la salud globalizada.

La metodología de trabajo es cuali-cuantitativa. El relevamiento de este sector se apoyó, a nivel contextual, en datos secundarios (censos y encuestas de carácter nacional). No obstante, éstos son deficitarios, ya que las investigaciones citadas muestran las dificultades de 
estudiar un sector con alto porcentaje de trabajo en negro.

Asimismo, se incluyó las entrevistas a informantes calificados y el uso de la técnica de observación directa en las obras de edificación de Rosario ${ }^{1}$ (Argentina), Montevideo ${ }^{2}$ (Uruguay), Porto Alegre ${ }^{3}$ y Goiânia (Brasil) y se realizaron encuestas semi-estructuradas a trabajadores de las dos primeras ciudades a causa de restricciones presupuestarias del ente oficial CONICET. En Brasil las obras que se enuncian en Porto Alegre se hicieron en compañía del sindicato y en Goiania junto a personal de la Fundaçao Jorge Duprat Figueredo de Segurança e Medicina do Trabalho (FUNDACENTRO).

Cabe señalar que mientras Rosario es la tercera ciudad del país, donde viven unos 35.493 obreros de la construcción según datos de la Encuesta Permanente de Hogares (EPH) de la provincia de Santa Fe, Montevideo, y la capital del país, posee unos 33.977 trabajadores registrados en el sistema de la seguridad social ocupados en unos 2000 centros de trabajo (PIT/CNT, 2000:64). Por último "existen cerca de 28.000 operarios trabajando en obras de la Capital y la Región Metropolitana de Porto Alegre" (El Gaúcho, 2000).

Las conclusiones de esta investigación, al apoyarse en estudios particulares de empresas privadas del sector formal de las ciudades antes mencionadas con más de 20 trabajadores, no son generalizables linealmente para la rama ni para la zona, el artículo sólo hará referencia a las limitaciones de los sistemas de cobertura de riesgos del trabajo y salud laboral en el MERCOSUR, seguido de una reflexión sobre las posibilidades de "prevenir siniestros y enfermedades" en el sector de la construcción.

1 En principio, en Argentina se realizaron encuestas a informantes calificados de: la Asociación de Arquitectos, el sindicato de trabajadores, la Secretaría De Obras Públicas Municipal, la Sec. de Trabajo de la Provincia de Santa Fe y la Fundación de Educación y Capacitación de los Trabajadores de la Construcción.

2 Los Informantes calificados de Uruguay fueron: Docentes de la Facultad de Sociología/UDELAR; Integrantes de la Sociedad de Arquitectos del Uruguay; Asociación Uruguaya de Seguridad; Docentes de la Facultad de Medicina/UDELAR; Comisión de seguridad en las obras del Sindicato Unico Nacional de la construcción y Anexos (SUNCA); Comisión de Salud y Medio Ambiente de la central sindical/ PIT/CNT; Cámara de la construcción del Uruguay; la Asesoría Médica y la Dirección de Inspección del Trabajo del Ministerio de Trabajo(MTSS); Banco de Previsión Social (B.P.S.) y CINTERFOR/OIT.

3 En Brasil se consultaron los registros datos provenientes del Ministerio de Trabajo y de Providencia y Asistencia Social y de la Fundación Instituto Brasileño de Geografía y Estadística (IBGE) y de FUNDACENTRO. Los informantes calificados de Porto Alegre fueron el Diretor en ejercicio del Sindicato dos Trabalhadores nas Industrias da Construçao Civil, la médica del trabajo y los inspectores de obra sindicales. También se acompañó a la visita a obra que evalúa el cumplimiento de las Condiçoes e Meio Ambiente do Trabalho na Industria da Construçao (NR 18) e ao Programa de controle Médico de saúde Ocupacional (NR 7), así como las charlas de "Educación para la Salud" dictadas por la médica. 


\section{Globalización, Estado y acuerdos del MERCOSUR}

Falta unanimidad en cuanto a la naturaleza de la globalización. Por un lado, Touraine (1999:32), señala que la globalización es un fenómeno económico, del que cabe destacar "la segunda mitad del siglo XIX, cuando la autonomía creciente de las fuerzas económicas escapa más y más a las reglamentaciones y prioridades impuestas por los Estados. El mundo occidental elude la dominación de lo político para permitir que el mercado organice una vida económica cada vez más diferenciada de los otros dominios de la vida social. El espíritu de la empresa, la ganancia capitalista, el dinero mismo, según George Simmel, destruyen las construcciones, los principios y los valores del orden social. En suma, hace ya tiempo que no se puede creer en el triunfo final de un Estado de Derecho capaz de manejar la dualidad propia de la modernidad".

Por otro lado, Castells (1998:273), señala que la globalización es también un fenómeno cultural, político y social. Desde esta última visión, "la capacidad instrumental del Estado resulta decididamente debilitada por la globalización de las principales actividades económicas, por la globalización de los medios y la comunicación electrónica y por la globalización de la delincuencia. La interdependencia de los mercados financieros y de divisas de todo el mundo, vincula las divisas nacionales de modo que el cambio contante entre dólares, yenes y el euro obliga a la coordinación de esas divisas como única medida capaz de mantener cierto grado de estabilidad en el mercado de divisas, la inversión y el comercio global. El resto de las divisas han quedado ligadas para todos los fines prácticos a este triángulo de riqueza. Si el tipo de cambio es interdependiente, también lo son las políticas monetarias, y por ende, si las políticas monetarias siguen cierta coordinación supranacional, también lo hacen las políticas presupuestarias".

"De ello se deduce que los estadonación individuales están perdiendo el control sobre elementos fundamentales de sus políticas. En general, el entrelazamiento de las economías nacionales y la dependencia de las finanzas del gobierno de los mercados globales y del crédito exterior, ha creado las condiciones para una crisis fiscal internacional de los estadonación, incluidos los más ricos. El control estatal sobre el espacio y el tiempo se ve superado por los flujos globales de capital, bienes, servicios, tecnologías, comunicación y poder. Su intento de apropiarse de la tradición y reconstruir la identidad nacional es desafiada por las identidades plurales definidas por los sujetos autónomos... Incluso el intento del estado por reafirmar su poder en el ámbito global, desarrollando instituciones supra-nacionales, socava más su soberanía... Cada vez resulta más contradictorio para las empresas operar en los mercados globalizados e integrados, mientras experimentan importantes diferencias de costes en prestaciones sociales, así como diferentes grados de regulación entre los países" (Castells, 1998:281).

Sin embargo, existen estudios que consideran que dicho autor conforma el grupo de los que aceptan la globalización de forma ahistórica, pero le adjudican un rostro humano, pues el dilema de este 
modelo es tratar de conectar los aspectos sociales negativos a una visión positiva del fenómeno globalizador. Continuando con tal enfoque, sostienen que las formas de gestión flexible están en pie de igualdad con formas precarias pero no tan flexibles, en tanto las relaciones laborales son necesarias para el desarrollo del modelo pero no imprescindibles. Continuando con ese razonamiento se afirma que existe otra visión histórica de la globalización que la considera una etapa de desarrollo, y de alguna manera hay que reducir sus efectos nocivos, aceptar lo positivo y adaptar las sociedades mediante un Estado árbitro. Sin embargo, también acá el concepto de trabajo se parece al anterior, pues la precarización laboral inunda con fuerza el nuevo marco de las relaciones laborales. Se ubican dentro de esta posición intermedia el teórico de la Tercera Vía Giddens, junto a André Gorz, A. Dabat y A. Ferrer (Korsunsky, 2001:14).

Por el contrario, existen teóricos que rechazan el modelo globalizador y podrían agruparse en dos posturas. La primera postura crítica incluye a una tendencia bastante amplia de aquellos que hablan de "mundialización" dentro de un proceso de apropiación y dominación mundial de los países centrales... y postulan un retorno hacia conceptos que revalidan los derechos de los ciudadanos y de los trabajadores que puede definirse como una vuelta sobre la protección social...en este caso el trabajo recupera las formas del trabajo asalariado. Este grupo está conformado por R. Sennet, P. Bourdieu y $R$. Antunes. La otra visión es una alternativa positiva y reformula una integración diferente a la perspectiva, pero positiva al expresar posibilidades y brin- dar proyectos alternativos, que desde el punto de vista de las relaciones laborales se busca la forma de redimensionar las mismas para conjurar los principios de solidaridad, igualdad y cooperación. Suele incluirse aquí a Greenpeace, al grupo ATTAC y al Foro Social Mundial (Korsunsky, 2001:17).

De todas las posturas antes mencionadas, "el concepto de mundialización para explicar el conjunto de cambios macroeconómicos que se han producido desde hace dos décadas en el capitalismo, nos parece de un grado mayor de adecuación explicativa, en tanto es una categoría de menor ambigüedad en relación al proceso asimétrico de desarrollo económico de las naciones en el nuevo contexto de regionalización y desregulación económica. Por lo tanto, como sostiene Boyer (Korinfeld y Alimena, 2001:5): la contradicción fundamental generada por la mundialización y que es fuente de desequilibrios que se expanden rápidamente hacia el conjunto de países con menor nivel de desarrollo relativo, se sitúa entonces entre, por una parte, el modo de regulación prevaleciente, que a pesar de sus transformaciones sigue operando a nivel nacional y, por otra parte, el régimen de acumulación liderado por las empresas multinacionales, cuyas regularidades en cuanto a la lógica de producción operan a nivel mundial y quedan fuera del poder regulador de los Estados".

En ese contexto se inscriben los datos provenientes de Europa que señalan los problemas derivados de "la globalización de la producción y la exportación de riesgos que caracterizan el comportamiento de algunas empresas europeas como el caso típico del traslado a Rumania de la producción de aislante desde 
una fábrica de Busseto, Italia, luego de la prohibición de amianto ${ }^{4}$ en dicho país durante 1981. Se transfiere la producción debido a la legislación y los sistemas políticos y administrativo débiles...no solo por el menor costo de la mano de obra, sino también para eludir las ataduras legislativas en materia ambiental y de seguridad" (Frigeri, 1999:7).

Esta retracción del papel del Estado también se vislumbra en las negociaciones del MERCOSUR, pues hasta el momento sólo se detectan dos eventos vinculados con salud: durante 1997 se firmó el Acuerdo Multilateral De Seguridad Social Del Mercado Común Del Sur del SGT № $10^{5}$, en tanto que durante 1999 se realizó VI Reunión Ordinaria de la Comisión de Vigilancia Epidemiológica y Control Sanitario de Puertos, Aeropuertos, Terminales y Pasos de Fronteras dentro del SGT № $11^{6}$. Cabe señalar que si bien se busca lograr el reconocimiento de los derechos a la Seguridad Social de los Trabajadores de cualquier nacionalidad, que prestan servicios en cualquiera de los Estados, así como a sus familias, todavía no fue aprobado por los parlamentos de Argentina y Paraguay. Asimismo cabe resaltar que los encuentros relativos a la salud omiten referirse a las condicio- nes específicas de los sectores productivos específicos (químicos, construcción, lácteos, automotores y textiles) y a la situación de aquellos trabajadores informales y sin cobertura social.

Dentro de las discusiones del subgrupo № 10 se destacan los operativos para el intercambio de experiencias en Inspección del Trabajo del sector Construcción que se realizaron en 1997 en Uruguay y Argentina y en 1998 en Brasil y Paraguay. Asimismo cabe señalar el Seminario Técnico sobre Investigación y Registro de Accidentes de Trabajo y Enfermedades Profesionales. En este último encuentro, se logró un acuerdo sobre las definiciones de: enfermedad ocupacional, accidente de trabajo, y accidente in itinere, sin hacer referencia a la situación de sectores productivos específicos (Comisión № III, Subgrupo № 10 del MERCOSUR, 1997:1).

También en 1998 y luego de 10 (diez) años se adoptó "La Declaración Socio-laboral" que establece el mínimo de derechos de los trabajadores y sostiene la adopción de "Principios y Derechos" individuales y colectivos, donde se destacan los artículos $16^{\circ}$ de Salud y Seguridad en el Trabajo y el 17 Inspección del Trabajo, que según la Coordinadora de

$4 \quad$ Las fibras del amianto se encuentran en el cemento, los tanques de agua, los caños fluviales y chapas, el aislante térmico, las instalaciones eléctricas, la plomería y la calefacción, lo cual produce neumoconiosis, silicosis, asbestosis, cáncer de pulmón y mesotelioma pleural, cáncer de estómago y la muerte.

5 El Subgrupo de Trabajo № 10 del MERCOSUR abarca tres comisiones temáticas: 1- Relaciones Laborales; 2- Empleo, migraciones, calificación y Formación profesional; y 3- Salud, seguridad; Inspección del Trabajo y Seguridad Social.

El Subgrupo de Trabajo № 11 del MERCOSUR se dedica a temas de salud. 
Centrales Sindicales del Cono Sur (CCSCS) aún no se han hecho efectivos (CCSCS, 2000:1).

Sin embargo, hasta el momento no se ha logrado armonizar la legislación sobre higiene y seguridad en las obras. Quizá esto se relaciona con lo que algunos estudiosos denominan la distinción hecha entre asimetrías armonizables y no armonizables, pues "mientras Argentina, Brasil y Paraguay poseen una legislación laboral fuertemente intervencionista, en Uruguay las relaciones laborales son fundamentalmente reguladas por acuerdos colectivos. Otro obstáculo proviene de la filosofía que sustenta cada norma laboral, pues la Argentina camina hacia la desregulación, Brasil procura una flexibilización pero manteniendo la reglamentación todavía fuertemente bajo la tutela del Estado, El Paraguay consagra en la constitución el intervencionismo en las relaciones individuales pero adopta los principios de la Organización Internacional del Trabajo en lo tocante a las relaciones colectivas, y el Uruguay privilegia las negociaciones colectivas (Assis de Almeida, 2000:6).

Particularmente, "los efectos de la integración y las formas de internacionalización en el sector de la construcción no han sido estudiados hasta aquí, porque tanto la construcción como los servicios públicos son vistos como sectores de actividad esencialmente domésticos, sin embargo, son los que van a cumplir una importante función de vinculación a nivel de infraestructura y servicios, para lograr la integración de territorio en el MERCOSUR y los primeros que ponen a prueba la falta de institucionalización porque exigen para ocurrir contratos de obra, de riesgo y de trabajo sin los cuales es impensable la construcción de una gran obra de infraestructura. El enfoque que predomina actualmente en los estudios de construcción es aquel dedicado a los Grandes Proyectos de Infraestructura y el impacto ambiental sobre el territorio de influencia, la generación de empleo y las ganancias producidas por el cobro de algún canon producido por la existencia de la obra de la que se trate. Sin embargo, faltan estudios de mayor utilidad como los estudios de transformación y la investigación de las nuevas reglas de juego de la integración regional, las nuevas formas de asociación empresaria, las formas combinadas de gestión del proyecto y de la mano de obra, la incorporación de nuevas tecnologías y la generación de inversiones conjuntas en los países del área" (Pania, 2000:1).

Es en esa senda, se pretende reflexionar sobre la modalidad de gestión de los trabajadores, en lo que respecta al abordaje de los riesgos del trabajo y su salud. Para tal fin, se parte de considerar que las condiciones en que viven, trabajan y consumen las personas, determinarán en gran medida su perfil de salud-enfermedad. Como puede verse este perfil no sólo expresa las condiciones de salud-enfermedad o muerte de un grupo humano, sino de todas en su conjunto. Cuando expresamos solamente las condiciones de enfermedad y muerte de un grupo humano le llamamos perfil patológico. Si se considera la noción de perfil de salud-enfermedad, el punto central de atención para estudiar y entender la salud debe cambiar casi en su totalidad. La tarea prioritaria es conseguir cada vez un mayor control sobre los elementos que 
determinan dicho perfil. Es decir, controlar cada vez más nuestros procesos vitales: el trabajo, las formas de consumo, las formas de organización, de cultura, de recreación, en suma, nuestra manera de reproducirnos en la sociedad. De esta manera, no interesa tanto luchar por prolongar la vida o por erradicar las enfermedades, sino tener la posibilidad de decidir de qué queremos enfermar y de qué queremos morir (Noriega, 1989:5).

\section{La salud globalizada}

EI MERCOSUR no es un bloque homogéneo, pues los cuatro países presentan notorias desigualdades. Esto es evidente cuando se analizan los indicadores que tienen relación con el desarrollo social del bloque, como se observa en la Tabla 1.

De las cifras anteriores se observa un marcada diferencia en la tasa de mortalidad infantil y expectativa de vida. Por esa razón, es diferente la situación social en la que se inscribe la salud de los trabajadores de cada país. De allí que sea necesario pensar en una visión globalizada de la misma, que evite el incremento de las desigualdades en los perfiles de morbi-mortalidad regionales a causa de la ex- portación de riesgos derivada de la globalización de la producción.

La salud de un país se ve afectada por la globalización de las enfermedades. Por un lado, hay una variedad de tuberculosis resistente a los antibióticos que puede viajar más rápidamente que el capital financiero... Por otro lado, el dengue y la malaria; que antes se limitaban a determinados lugares del mundo; se están propagando a nuevas regiones debido al cambio climático... Además, las enfermedades de "zonas calientes" como el virus del ébola, fácilmente podrán contagiar a todos los continentes. Esta difusión transnacional se debe a que la mala salud es causa de tanta pobreza; ya que esa es la principal causa de enfermedades y sufrimientos. Se estima que durante el siglo que comenzamos, la globalización de la enfermedad significará la interdependencia de la salud (Gro Harlem Brundtland, 1999:14), sobretodo en un sector caracterizado por aglutinar a inmigrantes laborales como el de la construcción.

En esa misma senda se inscribe el Programa de Formación en Salud Internacional de la Organización Panamericana de la Salud (OPS), a fin de profundizar las dimensiones internacionales del

\section{Tabla 1}

Indicadores socio-económicos del MERCOSUR. Año 1999

\begin{tabular}{lcccc}
\hline Indicadores & Argentina & Brasil & Paraguay & Uruguay \\
\hline Población total & 36.595 .000 & 168.458 .000 & 5.359 .000 & 3.312 .00 \\
Porcentaje de alfabetismo & 96,2 & 84,5 & 92,1 & 97,3 \\
Tasa de mortalidad infantil & 21,8 & 42,2 & 39,2 & 17,5 \\
Tasa de natalidad & 19,9 & 20,3 & 31,3 & 17,7 \\
Expectativa de vida (años) & 73,1 & 67,9 & 69,7 & 74,1 \\
\hline
\end{tabular}

Fuente: ALADI (2000). 
quehacer en salud y analizar los factores internacionales que afectan la realidad sanitaria. El primer objetivo del programa apunta: "a los principales problemas de salud de la región y profundizar sus determinantes políticos, económicos y sociales de origen nacional y transnacional. El propósito del mismo es desarrollar una visión amplia de las tendencias internacionales y regionales en salud y una comprensión profunda de la cooperación técnica en ese campo y busca movilizar y utilizar eficientemente los recursos políticos, financieros y técnicos apropiados de la comunidad internacional en pro del desarrollo social y sanitario de cada país" (OPS, 2000c:2).

Otra perspectiva similar fue la que sostuvo la organización de un encuentro internacional reciente de personas de habla hispana de todas las partes de los EEUU, Centro y Sur América, donde se han señalado algunas políticas tendientes a la armonización de la legislación, la capacitación y las acciones universitarias $^{7}$. En esa oportunidad, el workshops sobre "Salud de los Trabajadores Internacionales" elaboró un documento donde se identificaron aspectos comunes que son determinantes de la salud de los obreros de la construcción como: el escaso nivel educativo, la alta rotación y movilidad, el difícil acceso a la seguridad social, la informalidad, las condiciones cambiantes del trabajo, el carácter riesgoso de la actividad. Asimismo posee características comunes del sector informal como: el negrerismo o semi-esclavismo y la mayor propensión de accidentes conjugada con el hecho de establecer como prioridad a "la supervivencia" (OPS, 2000c:2).

Asimismo se definió como prioritario el hecho de que los tratados de comercio internacional deben proteger la calidad de vida en el trabajo y deben establecer una política pública de estado que responda a esta materia.

Es en ese contexto que se precisa una visión de la salud globalizada, capaz de identificar aquellos problemas derivados de la globalización de la producción y la exportación de riesgos, a los países con sistema político y legislación débil. Por esa razón es preciso analizar la legislación laboral y de higiene y seguridad de cada uno de los países miembros del MERCOSUR, a fin de evitar la agudización de las desigualdades. A continuación se detallan esos aspectos.

Dentro del contexto de valorización de la salud globalizada, es que recientemente obtuve una de las 10 Becas de la Panamerican Health Organization (WDC) y de National Safety Council (NSC), a fin de llevar los resultados parciales de la investigación en construcción a The Hispanic Forum on a Safe and Healthy Environment, en Estados Unidos. Este evento fue co-patrocinado por el Consejo Nacional de Seguridad (NSC), la Organización Panamericana de la Salud (OPS), la Agencia para la Protección del Medio Ambiente (EPA) y la Administración de Seguridad y Salud Ocupacional (OSHA). En esa oportunidad nos reunimos 150 representantes de organizaciones locales, nacionales e internacionales de las Américas, para identificar desafíos comunes, establecer alianzas estratégicas, y colaborar en el desarrollo de un plan de acción común (OPSa, 2000:1). 


\section{Las características del marco legal en los países del MERCOSUR}

Mozart Russomano, Profesor de la Universidad de Pelotas, Brasil, define el Derecho del Trabajo como: el conjunto de principios y normas tutelares que disciplinan las relaciones entre empresarios y trabajadores, o entre las entidades sindicales que los representan y otros hechos jurídicos resultantes del Trabajo. No obstante, señala que hoy día se observa que la agresión neoliberal, en una especie de venganza histórica, está cuestionando a fondo la propia existencia del Derecho del Trabajo (B.P.S, 2001:5).

El marco legal en que se inscriben las negociaciones del MERCOSUR está caracterizado por un derecho del trabajo que está siendo achicado por el crecimiento del sector informal de la economía, el avance de la tercerización (B.P.S., 2001:5). Este hecho se relaciona con los cambios del mercado de trabajo y con el surgimiento de nuevas formas de contratación generadoras de relaciones de trabajo atípicas, pues el contrato por tiempo determinado dejó de ser una excepción, admitiéndose varios contratos intermitentes, de temporadas y contratos de formación. Se verifica un significativo retroceso de la fuerza imperativa de las leyes del trabajo, admitiéndose que las convenciones colectivas se adapten con vista a sectores y empresas en crisis (Lobato de Paiva, 2000:1).

En ese contexto se inscriben las asimetrías entre las legislaciones nacionales, las contribuciones sociales y las cargas sociales de los Estados Partes que se detallan en el Cuadro 1 y la Tabla 2.
El análisis del cuadro revela que practicamente los principales derechos laborales existen en los cuatro países, de modo que las diferencias se presentan fundamentalmente en la extensión de los derechos asegurados. Sin embargo, las asimetrías "tienen un resultado importante sobre los costo de la mano de obra, conforme lo demuestra la Tabla 2, donde se exponen las contribuciones sociales en percentaje del salario pagodo al trabajador" (Assis de Almeida, 2000).

En ese sentido, existen otros estudios que indican que las cargas sociales en Brasil son $45,2 \%$ más altas que las argentinas, $112,3 \%$ más altos que las Uruguayas e $148,9 \%$ más altas que las paraguayas (Hubner, 2000:8).

Para el caso de la construcción es indispensable incorporar el estudio de la legislación específica de higiene y seguridad.

\section{La legislación de Salud Laboral e Higiene y Seguridad}

En Argentina, existe una legislación abultada que cambió radicalmente la cobertura de riesgos del trabajo desde 1996, creando la figura de las Aseguradoras de Riesgos del Trabajo (ART), que son operadores privados que aseguran a las empresas afiliadas, y las ayudan a elaborar sus planes de seguridad industrial y controlar que se cumplan.

La legislación incluye la Ley No 24.557 que sostiene que es obligación de los empleadores y las ART la de mantener registros de siniestralidad y enfermedades del trabajo y otras normativas. En primer lugar, existe la Resolución 231/96 


\section{Cuadro 1 \\ Las asimetrías entre las legislaciones nacionales de los Estados del MERCOSUR}

\begin{tabular}{|c|c|c|c|c|}
\hline Situación laboral & Argentina & Brasil & Paraguay & Uruguay \\
\hline $\begin{array}{l}\text { Jornada diaria } \\
\text { de trabajo }\end{array}$ & $8 \mathrm{~h}$ & $8 \mathrm{~h}$ & $8 \mathrm{~h}$ & $8 \mathrm{~h}$ \\
\hline $\begin{array}{l}\text { Jornada semanal } \\
\text { de trabajo }\end{array}$ & $48 \mathrm{~h}$ & $44 \mathrm{~h}$ & $48 \mathrm{~h}$ & $\begin{array}{l}44 \mathrm{~h} \text { (comercio) } \\
48 \mathrm{~h} \text { (industria) }\end{array}$ \\
\hline $\begin{array}{l}\text { Ferias anuales } \\
\text { remuneradas }\end{array}$ & $\begin{array}{l}14 \text { a } 35 \text { días co- } \\
\text { rridos, según el } \\
\text { tiempo de servi- } \\
\text { cio }\end{array}$ & 30 días corridos & $\begin{array}{l}12 \text { a } 30 \text { días co- } \\
\text { rridos, según el } \\
\text { tiempo de servi- } \\
\text { cio }\end{array}$ & $\begin{array}{l}20 \text { días útiles, su- } \\
\text { mando un día } \\
\text { para cada } 4 \text { anos } \\
\text { trabajados }\end{array}$ \\
\hline $\begin{array}{l}\text { Licencia por } \\
\text { maternidad }\end{array}$ & $\begin{array}{l}45 \text { días y } 45 \text { días } \\
\text { después del par- } \\
\text { to, pagos por los } \\
\text { empleadores y } \\
\text { compensados } \\
\text { por la Seguridad } \\
\text { Social }\end{array}$ & $\begin{array}{l}120 \text { días, pagos } \\
\text { por los emplea- } \\
\text { dores y compen- } \\
\text { sados por la Se- } \\
\text { guridad Social }\end{array}$ & $\begin{array}{l}6 \text { semanas antes } \\
\text { y } 6 \text { semanas } \\
\text { después, pagas } \\
\text { por la Seguridad } \\
\text { Social }\end{array}$ & $\begin{array}{l}6 \text { semanas antes } \\
\text { y } 6 \text { semanas } \\
\text { después, pagas } \\
\text { por la Seguridad } \\
\text { Social }\end{array}$ \\
\hline $\begin{array}{l}\text { Licencia } \\
\text { paternidad }\end{array}$ & 2 días & 5 días & 2 días & $\begin{array}{l}\text { No hay previsión } \\
\text { legal }\end{array}$ \\
\hline $\begin{array}{l}\text { Alistamiento elec- } \\
\text { toral }\end{array}$ & $\begin{array}{l}\text { No hay previsión } \\
\text { legal }\end{array}$ & 2 días & $\begin{array}{l}\text { No hay previsión } \\
\text { legal }\end{array}$ & $\begin{array}{l}\text { No hay previsión } \\
\text { legal }\end{array}$ \\
\hline $\begin{array}{l}\text { Fallecimiento } \\
\text { del cónyuge } \\
\text { o pariente }\end{array}$ & 3 días & 2 días & 4 días & $\begin{array}{l}\text { No hay previsión } \\
\text { legal }\end{array}$ \\
\hline Casamiento & 10 días & 3 días & 3 días & $\begin{array}{l}\text { No hay previsión } \\
\text { legal }\end{array}$ \\
\hline Greve & Posible & Posible & Posible & Posible \\
\hline $13^{\circ}$ salario & 1 mes de salario & 1 mes de salario & 1 mes de salario & 1 mes de salario \\
\hline $\begin{array}{l}\text { Participación } \\
\text { en los lucros }\end{array}$ & $\begin{array}{l}\text { - La constitución } \\
\text { prevé } \\
\text { - Ausencia de ley } \\
\text { reglamentando } \\
\text { - Ausencia de uti- } \\
\text { lización práctica }\end{array}$ & $\begin{array}{l}\text { Prevista en la } \\
\text { constitución y re- } \\
\text { gulada por ley }\end{array}$ & $\begin{array}{l}\text { - No prevista en } \\
\text { la ley } \\
\text { - En la práctica } \\
\text { negociación co- } \\
\text { lectiva }\end{array}$ & $\begin{array}{l}\text { No hay previsión } \\
\text { legal }\end{array}$ \\
\hline $\begin{array}{l}\text { Dimisión sin justa } \\
\text { causa }\end{array}$ & Posible & Posible & $\begin{array}{l}\text { Estabilidad des- } \\
\text { pués de } 10 \text { años } \\
\text { de trabajo para el } \\
\text { mismo emplea- } \\
\text { dor }\end{array}$ & Posible \\
\hline
\end{tabular}




\section{Cuadro 1 (Continuación)}

\begin{tabular}{|c|c|c|c|c|}
\hline $\begin{array}{l}\text { Indemnización } \\
\text { en la Dimisión } \\
\text { sin justa causa }\end{array}$ & $\begin{array}{l}\text { - Aviso previo de } \\
30 \text { días (si el } \\
\text { empleador tu- } \\
\text { viera menos de } \\
5 \text { años de servi- } \\
\text { cio en la empre- } \\
\text { sa) o de } 60 \text { días } \\
\text { (si tuviera más } \\
\text { de } 5 \text { años) } \\
\text { - } 1 \text { mes de salario } \\
\text { por cada año de } \\
\text { servicio }\end{array}$ & $\begin{array}{l}\text { - Aviso previo de } \\
30 \text { días } \\
\text { - Recibimiento do } \\
\text { FGTS (equiva- } \\
\text { lente a } 1 \text { mes de } \\
\text { salario por año } \\
\text { trabajado) } \\
\text { - Recibimiento de } \\
40 \% \text { del saldo } \\
\text { de FGTS, pa- } \\
\text { gos por el em- } \\
\text { pleador }\end{array}$ & $\begin{array}{l}\text { - Aviso previo de } \\
30 \text { a } 90 \text { días } \\
\text { - Recibimiento de } \\
15 \text { días de sala- } \\
\text { rio por cada año } \\
\text { trabajado }\end{array}$ & $\begin{array}{l}\text { - No hay aviso } \\
\text { previo } \\
\text { - Recibimiento de } \\
1 \text { mes de salario } \\
\text { por cada año de } \\
\text { servicio (limita- } \\
\text { do a un techo } \\
\text { equivalente a } 6 \\
\text { meses de remu- } \\
\text { neración) }\end{array}$ \\
\hline $\begin{array}{l}\text { Seguro } \\
\text { Desempleo }\end{array}$ & $\begin{array}{l}\text { - } 80 \% \text { del mayor } \\
\text { salario de los út- } \\
\text { timos } 6 \text { meses, } \\
\text { con un techo de } \\
\text { US\$ 400,00 y } \\
\text { un piso de US\$ } \\
120,00 \\
\text { - De } 4,8, \text { o } 12 \\
\text { meses, confor- } \\
\text { me el tiempo de } \\
\text { contribución en } \\
\text { los últimos } 3 \\
\text { años } \\
\text { - Financiado con } \\
\text { contribución pa- } \\
\text { tronal de } 1,5 \% \\
\text { sobre la hoja de } \\
\text { sueldo }\end{array}$ & $\begin{array}{l}\text { - Valor igual a } \\
\text { percentual de la } \\
\text { media de los sa- } \\
\text { larios de los últi- } \\
\text { mos tres me- } \\
\text { ses, con un te- } \\
\text { cho de } 2 \text { sala- } \\
\text { rios mínimos y } \\
\text { piso de } 1 \text { salario } \\
\text { mínimo } \\
\text { - Duración de } 3 \text { a } \\
5 \text { meses por pe- } \\
\text { ríodo adquisiti- } \\
\text { vo } \\
\text { - Financiado por } \\
\text { el Poder Público } \\
\text { y por la iniciativa } \\
\text { privada }\end{array}$ & $\begin{array}{l}\text { No hay seguro } \\
\text { desempleo }\end{array}$ & $\begin{array}{l}\text { - } 50 \% \text { de la me- } \\
\text { dia mensual de } \\
\text { las remunera } \\
\text { ciónes de los út } \\
\text { timos } 6 \text { meses, } \\
\text { con un techo de } \\
8 \text { salarios míni- } \\
\text { mos y un piso } \\
\text { de } 0,5 \text { salarios } \\
\text { mínimos } \\
\text { - Tanto cuanto el } \\
\text { empleador es } \\
\text { tuviera desem- } \\
\text { pleado hasta el } \\
\text { máximo de } 6 \\
\text { meses } \\
\text { - Financiado por } \\
\text { la Providencia } \\
\text { Social }\end{array}$ \\
\hline
\end{tabular}

Fuente: Assis de Almeida (1996).

Tabla 2

Las cargas sociales en los Estados del MERCOSUR

\begin{tabular}{cccc}
\hline Brasil & Argentina & Paraguay & Uruguay \\
\hline $102,06 \%$ & $70,27 \%$ & $41,00 \%$ & $48,06 \%$ \\
\hline
\end{tabular}

Fuente: Assis de Almeida (2000). 
del 22 de noviembre de 1996 reglamentada en el Decreto 911, donde se especifican las actividades de prevención a los 7 y a los 15 días de iniciadas las obras y las horas de asignación profesional en forma semanal sin distinción entre Servicio de Higiene y Seguridad interno y externo (integrados por médicos y técnicos o ingenieros de higiene y seguridad).

Se prevé la entrega de las ropas de trabajo se prevé a los 7 días del inicio de la obra. En tanto, a los 15 días se realiza lo siguiente: completar la capacitación básica en Higiene y Seguridad, instalar carteles de seguridad, consignar un sitio para comedor, completar la protección de incendios y adecuar el orden y la limpieza de la obra destinando sectores libres de obstáculos para la circulación.

En segundo término, la Resolución 231/96 establece las condiciones básicas desde el comienzo de la obra, donde se observa un Legajo Técnico conformado por: memoria descriptiva de la obra, programa de prevención de accidentes y enfermedades de acuerdo a los riesgos previstos en cada etapa... Además, se verifica la instalación de baños, vestuarios, comedor y la entrega de ropas (que debió llevarse a cabo a los 7 días).

En tercer lugar, la Resolución $51 / 96$ indica que los empleadores de la construcción deberán comunicar a su ART con un mínimo de 5 (cinco) días de anticipación, la fecha de inicio de todo tipo de obra. Lo novedoso es que el reporte incluye: el contratista principal y los subcontratistas, la nómina del personal actualizada, la fecha de confección del Programa de Seguridad con la firma del empleador, el director de obra y el res- ponsable de higiene y seguridad (aprobado por la ART).

Asimismo, la Resolución 35/98 establece un mecanismo para la coordinación en la redacción y verificación de un Programa de Seguridad Único a cargo del comitente o contratista principal. También dictamina que el Servicio de Prevención de la ART de cada subcontratista controle el cumplimiento del plan.

Finalmente, la Resolución № 319/ 99 establece la responsabilidad de la coordinación de acciones en el caso de que hubiera más de un contratista principal o no hubiera ninguno. Asimismo, se refiere a "la obra repetitiva y de corta duración" que es aquella cuya ejecución no exceda los 7 (siete) días corridos y a los Servicios de Medicina.

A pesar de las numerosas previsiones legales, la tarea de los profesionales de la medicina y de la higiene y seguridad en obra es insuficiente. Con respecto a los servicios médicos, su tarea se reduce a los exámenes pre-ocupacionales en algunas grandes obras de infraestructura 0 en algunas empresas multinacionales. Con respecto a los servicios de higiene y seguridad, existe un grupo de profesionales con sobrecarga de trabajo debido los bajos sueldos otorgados por los empresarios del sector, que visita la obra muy pocas veces al año, generalmente durante la excavación. Por otro lado, tampoco se ocupan de la gestión preventiva de los riesgos la mayoría de los profesionales con estabilidad laboral (pertenecientes a los servicios internos), aludiendo que carecen "de estímulos profesionales" derivados de la legislación. 
Este hecho persiste por falta de sustento gubernamental, pues la Inspección del Trabajo del MTSS carece del personal y el presupuesto suficiente destinado a realizar visitas periódicas a las obras (posee 40 personas para todo el país). Este hecho agrava la situación de inseguridad en las obras, si se suma aquel rol ambiguo y contradictorio de las ART, que las obliga a ser fiscalizador de su propio socio: el empleador. Por eso, sólo han invertido en reparar los daños y no en prevencióno en visitas a los lugares de trabajo.

La situación de desprotección estatal se ha profundizado con la última modificación legislativa (Ley 1278/00) que pareciera salir en auxilio de las ART y en perjuicio de los trabajadores, ya que reduce el universo de inspección nacional de la S.R.T. a unas 3.412 empresas y 812.806 trabajadores, del total de 430.000 empleadores afiliados al sistema y de los 4.988 .000 trabajadores asegurados durante el ano 1999. Esto significa cubrir un $47 \%$ de la siniestralidad total a través del Plan de Acción para empresas críticas con un índice de incidencia de $10 \%$ superior a la media del sector. La misma ha generado un enorme rechazo dentro de los abogados laborales, según declaró el Presidente de la Asociación Argentina de Abogados Laborales porque afirman que "de esta forma hay una prevención al revés, porque se hará prevención sobre el mayor índice de siniestralidad...o sea una vez que ocurrieron los hechos. ¡El trabajador se tendrá que enfermar, que accidentar y que morir para que vayamos a verlo!" (Ramírez, 2001:1).

El sistema es injusto pues de un lado están las A.R.T. que son S.A. con técnicos y profesionales especializados, y por el otro lado, está el trabajador que carece de técnicos y profesionales que los asesoren, y ni el sindicato lo defiende... si por lo menos hubiera un tercero que mediara, como el Estado... Este hecho se constata cuando se observa que la variable de ajuste de las A.R.T. son las prestaciones, pues "las hernias no son accidentes y los problemas de columna no son enfermedad. Incluso, del total de siniestros laborales cubiertos, que asciende a unos 440.000 , sólo un $1,2 \%$ son enfermedades profesionales, lo cual no puede interpretarse como indicador de una población sana " (Ramírez, 2000:1), sino de un ocultamiento deliberado.

En Brasil, la constitución nacional de 1988 responsabiliza al ministerio Público de la protección de los intereses relacionados con el medio ambiente de trabajo y la salud de los trabajadores (art. 129, inciso III Constitución Federal). Además, existe las normas Reglamentadora de Seguridad y Salud del Trabajo NR 18, sobre Condiciones y Medioambiente de trabajo en la industria de la construcción destinada a los empleadores de más de 20 trabajadores. Destaca la obligatoriedad del envío del Programa de Condiciones y Medioambiente de Trabajo (PCMAT) a la Delegación Regional de Trabajo, donde se inscriban las actividades y operaciones que entrañen riesgos de accidentes y enfermedades del trabajo, así como sus respectivas medidas preventivas. Por ese motivo, se hace alusión a las etapas de demolición, excavación y estructura, y se incluyen las operaciones de soldadura y corte; carpintería, armadura de acero. 
La misma hace referencia a las condiciones de bienestar del ámbito laboral (vestuario, baños, comedor, lavandería, lavatorios y cocina). Luego detalla las condiciones requeridas de: rampas, escaleras, medidas de protección contra caída de altura, andamios, instalaciones eléctricas, locales confinados, máquinas y herramientas, almacenamientos y transporte de personas y de materiales. Cabe resaltar que está prevista la participación de los propios obreros en las Comisiones Internas de Prevención de Accidentes (CIPA), para tornar compatible permanentemente el trabajo con la preservación de la vida y la promoción de la salud en el trabajo ${ }^{8}$.

Otro hecho destacable de la NR 18 es la creación de Comités Permanentes Nacionales y Comités Permanentes Regionales con la participación tripartita de gobierno, empresarios y trabajadores que tienen, entre otras, las siguientes tareas: estudiar o proponer medidas para el control y mejoría de las condiciones de trabajo, proponer campañas, elaborar datos de siniestralidad y enfermedad, elaborar propuestas encaminadas para la autoridad competente y el ministerio publico responsable (Silva, 2001a:7).

Sin embargo, por un lado, los órganos fiscalizadores presentan carencias; $y$ por el otro, existen algunos sindicatos que se mantienen ajenos a la problemática de la seguridad y la salud (OIT, 1999:1). Incluso, "Todavía persiste la cul- tura de tener un médico del trabajo o un técnico/ingeniero de seguridad solo para cumplir con la formalidad. La cultura prevencionista es difícilmente aceptada como una cosa factible y necesaria" (Litchtenberg, 2000:1).

Aún así, y a diferencia de los otros países del MERCOSUR, el Ministerio de Trabajo de Brasil periódicamente realiza congresos, seminarios y jornadas de capacitación en las diferentes regiones del país, financiando la asistencia masiva de especialistas del área. Además posee políticas de difusión de la normativa, de investigación y de capacitación en manos de FUNDACENTRO. La misma ha diseñado diferentes videos y manuales de seguridad e higiene, acordes al lenguaje y la cultura de profesionales, cuadros medios, capataces y obreros.

Otra característica específica de Brasil es la tarea de inspección del trabajo que realizan numerosos sindicatos de Brasil, observando el cumplimiento de la normativa laboral vigente (normas de higiene y seguridad, prestaciones sociales, aportes patronales y cuota sindical). Dentro de ellos, se destacan los sindicatos de Río de Janeiro, Sâo Paulo y Porto Alegre, quienes además poseen profesionales del campo médico y/o de higiene y seguridad que realizan tareas de sensibilización de los trabajadores dentro de la jornada de trabajo, referidas a la prevención de enfermedades y accidentes (Litchtenberg, 2000:1).

8 Esta normativa altera la reglamentación № 5, que se refería a la Comissào interna de Prevençao de Acidentes e dá outras providencias. MTEE. Portaria № 8, de 23 de fevereiro de 1999. Brasil. 
El último aspecto fundamental lo constituye la Tripartita que funcionan en lo diferentes estados de manera particular, las cuales frecuentemente discuten los problemas de seguridad en la obra, las responsabilidades compartidas y las estrategias de solución. Esta figura jurídico-política que actúa ante los casos puntuales sólo existe en Brasil, aunque adquiere características disimiles según la organización de los actores sociales de cada región y cada estado.

En Paraguay existe la ley № 213/93 dedicada a todos los sectores productivos, que indica la obligación de empleadores, trabajadores y Estado, tendiente a que el trabajador tenga derecho a una protección en materia de salud, seguridad e higiene (art. 272), con una política de prevención de riesgos ocupacionales, o conjuntos de técnicas, estudios y acciones encaminadas al perfeccionamiento de las condiciones ambientales, organizativas y personales destinadas a evitar el daño o alteraciones a la integridad física, funcional o psicológica (art. 273). Lamentablemente, según opiniones de algunos sindicalistas, el gobierno carece de una estructura mínima a nivel del organismo encargado de fiscalizar las condiciones de seguridad y salud (OIT, 1999:1).

Según el Ingeniero Pazos de la cámara empresaria uruguaya, la situación se agrava en un contexto donde conviven tres sindicatos paraguayos, con un papel desdibujado "hay que ver que representatividad tiene el sindicato de Paraguay ante un empresariado tan poderoso,... pues en la reuniones del MERCOSUR siempre hemos visto a los empresarios, pero nunca vimos a los sindicatos" (Silva, 2000b:14). Un sector del mismo se ha incorporado recientemente a los talleres regionales sobre formación de formadores de la OIT, dedicados a contribuir al mejoramiento de las condiciones de Seguridad y Salud en la construcción, mediante el cambio cultural y el intercambio de experiencias sindicales.

Por último, en Uruguay existe una abultada reglamentación, donde se destacan los Decretos 89/95 y 283/96. El primero establece la obligatoriedad del "servicio técnico de seguridad" en obras con más de cinco obreros, más de 8 metros de altura $\circ 50$ de profundidad, junto a la participación de un delegado de seguridad de los trabajadores que debe ser un oficial con más de 2 años de antigüedad. El segundo hace alusión a la obligatoriedad de la empresas de realizar un plan de seguridad antes de iniciar la obra (planos y memoria de andamio).

En este caso ha sido importante la participación activa de el Centro Interamericano de Investigación y documentación sobre Formación Profesional de la OIT (CINTERFOR), quien promovió las negociaciones entre empleadores y trabajadores desde 1993, año de mayor conflictividad laboral a causa de las altas tasas de siniestros mortales. La misma generó numerosas actividades de Capacitación y formación en Seguridad e Higiene, e incentivó la Comisión Tripartita de la Construcción. Actualmente dicho organismo ha promovido la evaluación de tareas, donde participaron el sindicato de trabajadores, los empresarios y CINTERFOR, a fin de redefinir las categorías de trabajadores de acuerdo a los cambio de la organización del trabajo (Montanaro, 2001:2).

Pareciera que el control del cumplimiento de la normativa fue descendiendo 
debido a la falta de recursos económicos (instrumentos de trabajo, vehículos y viáticos) y de personal del Ministerio del Trabajo. Este hecho se observa al analizar los datos difundidos por los propios funcionarios gubernamentales que indican que poseen 86 inspectores para Montevideo y El Interior del país, 56 inspectores de documentación laboral y 28 inspectores de Ambientes de Trabajo (MTSS, 2001:2).

Si bien la normativa establece que el MTSS tiene el cometido de controlar y fiscalizar las condiciones de trabajo del país e investigar las causas de los accidentes que se producen, en la practica su accionar esta mas limitado. Según datos obtenidos en la Asesoría Médica del Ministerio de Trabajo de Uruguay, lamentablemente en la práctica sólo se entera por dos vías: 1) la denuncia de un trabajador, 2) la prensa oral, escrita o televisiva (Silva, 2001b:13). Por tal motivo la información es totalmente insuficiente pues falta normatizar los sistemas de comunicación, e incluso faltan criterios unificados en las entidades involucradas en el diagnóstico, la asistencia y la prevención de los siniestros laborales y enfermedades, sumado al subregistro de datos sobre enfermedades profesionales y accidentes de trabajo y el atraso de 3 años en la publicación de datos (OPS, 2000b:3).

En la práctica, lamentablemente existen dificultades de implementación de la legislación. Según el representante de la Asociación Uruguaya de Seguridad, los técnicos prevencionistas pueden ejercer en forma particular o estar afiliados a la Asociación de Promotores Privados de la Vivienda de Uruguay (APPVU), que aglutina a inversionistas, los cuales sue- len estar a cargo a un número excesivo de empresas, generando una práctica exclusivamente administrativa acompañada de escasas visitas a obra (Silva, 2000b:2).

Hasta el año pasado, Uruguay era el país que presentaba una disminución de los accidentes mortales dentro del personal con cobertura social, ya que mientras en 1996 se producían 16 casos fatales, en 1999 se registran 8 muertes. Lamentablemente en la actualidad se ha revertido esta situación, porque en un mes del 2001 se produjeron 7 muertes en Uruguay, que el sindicato atribuye a la suspensión de las inspecciones gubernamentales en el Interior y en Montevideo desde septiembre del 2000 aproximadamente (La República, 23/01/01:29). E MTSS replicó las acusaciones, señalando que los siniestros se produjeron en el sector informal y durante el período de licencia de la construcción, por lo que no tiene relación de causalidad alguna con la actuación de dicha secretaría (La República, 23/01/01:29).

De todo lo antes mencionado se concluye que dentro de los 4 países existe un retiro progresivo del estado de las tareas de inspección de las condiciones de trabajo, seguridad y salud, aunque en Brasil es donde el mismo se encuentra en estado incipiente. Esta retracción del Estado se relaciona con un sistema de cobertura de riesgos del trabajo heterogéneo, que se detalla en la sección siguiente.

\section{Cobertura de riesgos del trabajo: prestaciones y gestión}

Es preciso señalar que existen al menos, tres sentidos del concepto de co- 
bertura: 1) cobertura legal o teórica, que refiere al nivel de cobertura exigido o establecido por la normativa (fundamentalmente por los convenios de OIT $102 \mathrm{y}$ 128); 2) cobertura estadística, que refiere al número de activos que están registrados en el sistema, obviamente mucho más aproximado a la realidad; y 3) la cobertura real, que refleja lo que sucede en la realidad en cuanto a la protección. La cobertura abarca en general más a los sectores formales y de mayores ingresos; y menos (o nada) a los de menores ingresos o informales. El campo de aplicación puede ser determinado de tres maneras: referido a los asalariados, a la Población Económicamente Activa (PEA) y a los residentes del país. No obstante, la práctica presenta dificultades que principalmente se observan en los registros estadísticos, que difieren según la fuente de información, y los métodos utilizados para la eventual medición (Bruni, 1998:4).

El estudio realizado por el B.P.S durante 1998 señalaba que se aprecia claramente una disminución en la cobertura a medida que pasan los años, pese a la diferencia de maduración de los sistemas de la seguridad social que se han reformado ( 16 años en Chile, 3 años en Argentina, 2 en Uruguay) y por otro lado, que no han mejorado o directamente han empeorado, la cobertura existente antes de la implantación de los sistema privados. Para tal fin, ofrece datos a diciembre de 1997 en los 3 países, para la relación afiliados/cotizantes, dado que la cobertura está fundamentalmente determinada por el nivel de aportes a la cuenta individual de cada trabajador, además de la rentabilidad obtenida y la expectativa de vida al momento de jubilarse, en general Ver Tabla 3.

La realidad de cobertura en los nuevos sistemas, se agrava mucho para el creciente informalismo y para los trabajadores independientes, autónomos o unipersonales, como se les llama en cada uno de los 3 países respectivamente (Bruni, 1998:5).

Los cuatro países poseen diferentes coberturas de riesgo, prestaciones y gestión. En Argentina, los riesgos del trabajo están cubiertos por las ART que establecen primas según el riesgo de la actividad a cubrir y las condiciones de seguridad de la empresa. Pero, este seguro no exime a los empleadores por los accidentes que puedan ocurrir en su establecimiento.

Sin embargo, el sistema en sí, tiene dificultades provenientes del incumplimiento de las normas de seguridad por parte de las empresas. Algunos empre-

\section{Tabla 3 \\ Porcentaje de cobertura de riesgos y relación afiliado/cotizante en tres países del Cono Sur}

En Chile, cae del 74 en 1982 al 57\% en 1997 (43\% de no cotizantes).

En Argentina, cae del 63 en 1994 al 52\% en 1997 (48\% de no cotizantes).

En Uruguay, cae del 67 en 1996 al 53\% en 1997 (47\% de no cotizantes).

Fuente: Bruni, J. (1998). 
sarios consideran al sistema como un seguro más, donde pagan una alícuota mensual y se desligan; en cambio, otras empresas han consensuado con las ART para trabajar en prevención, capacitar a sus obreros y bajar los costos.

Esta situación se relaciona con las carencias del médico laboral, pues faltan tareas médicas preventivas, como ellos mismos lo reconocen: "los médicos no recorremos los ámbitos de trabajo... y no se agrega, al registro estadístico, una tarea periódica de recorrida y observación en el ambiente laboral" (Zlatkes, 1999:1). Su tarea suele reducirse a los exámenes pre-ocupacionales y/o al control burocrático de ausentismo.

En el caso de Brasil, la organización administrativa de los riesgos está a cargo del Ministerio de Previsión y Asistencia Social (supervisión general); del Instituto Nacional de Seguridad Social (administración de prestación en efectivo), y el sistema Unificado de Salud, y el Ministerio de Salud (administración de las prestaciones médicas) (Conte-Grand y Rodríguez, 1999:239).

En cuanto las normas de seguridad y salud, cabe resaltar que las mismas son revisadas por las Comisiones Tripartitas y paritarias con amplia participación de la sociedad, a fin de evitar la superposición y el conflicto institucional. Este fenómeno se reitera dentro del Sistema Único de Salud descentralizado, que convive con numerosos sistemas de registro de morbi-mortalidad como: el SIM (mortalidad), el SIH/SUS (información hospitalaria), el SIAMB/SUS (información ambulatoria que aporta datos del "trabajo informal" y "trabajo en negro"), el SINAM (dolencias de notificación obligatoria), y el SIB (aten- ción básica en los barrios y generada incluso por los mismos agentes comunitarios), el cartào nacional de saúde y la rede Integrada de todas las universidades/RIPSA. Dicho sistema está sufriendo modificaciones constantes. Por un lado, se pasó de una lista de 26 enfermedades ocupacionales, a un número de 210 enfermedades, incluyendo algunas ligadas a la salud mental como el stress y el pánico (Fabel, 2000:1).

Por otro lado, recientemente, el Ministerio de la Providencia lanzó un anteproyecto de ley, que transfiere al sector privado todos los procedimientos que envuelven las enfermedades ocupacionales, y el seguro de accidente deja de ser solventado por el gobierno y pasa a ser responsabilidad de la empresa (Serviço de Noticias del Correio Sindical do Mercosul № 36, 2000a:2). Tal proceso de privatización está siendo cuestionado, porque "contraría la idea de seguridad social expresa en la Constitución Federal, ya que su esencia es el carácter público y universal; donde las acciones de salud, seguridad y asistencia social están integradas...en cambio, el proyecto nuevo se basa en la lógica de la lucratividad, que impera en contra de las garantías y derechos constitucionales, pues los trabajadores son excluidos de los procesos de control y gestión de los recursos del SAT (DIESAT, 2000:2).

En el caso de Paraguay, la organización administrativa de los riesgos del trabajo, se encuentra en manos del Instituto de la Seguridad Social (administración de aportes y contribuciones). Sin embargo, apenas un $17 \%$ del total de los asalariados posee un seguro social del Instituto de Previsión Social, siendo el 
país con más baja cobertura médica laboral de toda la región del Plata (Informativo Laboral del CDE, 2000:29).

Esto se agrega al hecho de que "prácticamente no existe la vigilancia epidemiológica en el país, porque no hay un diagnóstico que diga de qué se enferman $y$ accidentan los trabajadores en general... y menos en una obra en construcción, pues cuando el Instituto de la Seguridad social decide concurrir al lugar de trabajo, se encuentra con que la obra se terminó" (Fleitas, 2000:1).

Por último, en Uruguay la responsabilidad administrativa recae sobre el Banco de Seguros del Estado (B.S.E.). Desde 1994 se desmonopoliza el mercado de seguros, permitiendo la entrada de aseguradoras privadas en todos los seguros, a excepción del de accidente. Esto ha generado que grandes empresas contraten todo el resto de los seguros (contra robo, incendio, riegos contra terceros y flota) menos los accidentes. De esa forma el banco posee dos problemas, por un lado, no recupera lo perdido en un siniestro mortal, y por otro lado, se determinó que de cada 100 gestiones sólo se obtienen $4^{9}$ recuperaciones.

Por esa razón desde 1996 el B.S.E. deja de publicitar en boletines anuales, los informes de morbi-mortalidad laboral. Este hecho fue resaltado por docentes de la Facultad de Medicina (UDELAR), médicos laborales del Ministerio de la Seguridad Social (MTSS) y representantes de la Asociación de Higiene y Seguridad en el Trabajo de Uruguay. Los mismos señalan que tiene relación con la probable privatización del seguro de accidente. Esta situación antecede a los recientes anuncios del presidente de Uruguay sobre la desmonopolización del seguro de accidente, que establece un seguro privado a cargo del trabajador y no como ocurre actualmente, que le debe pagar el empleador (Correio sindical do Mercosul, 2000b:2).

También faltan criterios unificados en las entidades dedicados a la asistencia de siniestros laborales y enfermedades. En cuanto a la primera, cada una reconoce algo diferente, según sea de: los servicios de salud en el trabajo público, los servicios de salud en el trabajo privado, la salud pública, y la salud privada. En cuanto a los siniestros, existen datos en B.S.E., el Ministerio de Salud Pública, el área de Toxicología y de salud laboral del B.P.S. y los servicios de salud laboral ${ }^{10}$. Además, si bien existe un carnet de salud, no todos los trabajadores se lo hacen, pues ni las empresas ni los estados lo exigen. En ese sentido, durante las entrevistas realizadas a los trabajadores, manifestaron que para realizar el trámite, perdían el pago por el jornal trabajado.

9 Graside, Ronald es un dirigente sindical del SUNCA que pertenece a la Comisión Nacional de Salud y Seguridad Ambiental del PIT-CNt que fue entrevistado en Montevideo, Uruguay, el día 08 de mayo de 2000.

10 Entrevista realizada al Dr. Daniel Danatro, Asesor médico del Ministerio de Trabajo de Uruguay, Montevideo, mayo de 2000. 
La construcción tiene un régimen especial que es el aporte unificado, que significa que por cada peso que invierte, aporta la misma cifra a la seguridad social, que lo recauda el B.P.S., donde se incluye el seguro de accidente. El banco luego lo envía al B.S.E. Este incluye además de la seguridad social, licencia, aguinaldo y seguro vacacional.

A diferencia de Argentina, existen numerosos arquitectos que poseen una formación de post-grado en higiene y seguridad. Pero todavía existen conflictos de competencia y responsabilidades, porque según opiniones vertidas por la Comisión Directiva de Higiene y Seguridad de la Asociación de Arquitectos de Uruguay "falta claridad sobre los alcances de las disciplinas en lo que hace al estudio de seguridad, donde se requiere del arquitecto técnico de obra, porque el decreto establece responsabilidades "a priori" a gente que no se siente responsable, pues él (técnico prevencionista) hace prevención, y nosotros ponemos la firma". Sin embargo, según la opinión de la propia asociación, aún persisten los siguientes poblemos: 1) en las obras prima lo económico; 2) existe diferencia entre Montevideo y el Interior, porque allí falta información de los propios arquitectos y no se registran las obras; $y 3$ ) Ias mayores complicaciones se producen en obras por administración, que son un puente entre lo formal e informal (Comisión Directiva de Higiene y Seguridad de la Asociación de Arquitectos de Uruguay, 2000:3).

Por último cabe resaltar que si bien los países poseen diferentes sistemas de cobertura, lo que realmente interesa revisar es la antinomia: monetización de riesgo versus transformaciones productivas, ya que existen numerosas experiencias donde las empresas ofrecen ( $y$ los sindicatos reclaman) aumentos de salario como compensación monetaria a la nocividad y los riesgos laborales (Berlinguer, 1993:208). En suma, cabe analizar el comportamiento de empresarios, sindicatos, y aseguradoras, que basados en la visión compensatoria del riesgo, promueven acciones donde "se cambia vida por un plus por riesgo de altura"...; "se cambia enfermedad por premio al presentismo". Desde esta visión se pretende compensar o indemnizar el daño ocasionado, evadiendo acciones colectivas de carácter preventivo, que poseen un mayor impacto en la gestión preventiva de los riesgos a la salud.

\section{La situación particular del sector de la construcción}

Los estudios del MERCOSUR señalan que la movilidad de la demanda es muy alta, pero no así la de la oferta. De allí que se dan extensas áreas caracterizadas por mano de obra costosa, poco flexible y áreas en las cuales la oferta de trabajo es menos costosa y muy flexible. Lamentablemente recién se están realizando las homologaciones estadísticas para hacer comparables las mediciones de los países, que tienen diferencias en la definición de la desocupación y carecen de cifras de la subocupación. Tampoco es posible trabajar con cifras de los trabajadores declarados y no declarados de cada país y con saldos migratorios válidos de migrantes legales e ilegales (Panaia, 2000).

No obstante, se sabe que el trabajo en la obra se produce en un marco donde proliferan relaciones laborales precarias 
debido a la existencia de trabajadores de tiempo parcial, por tiempo determinado, servicios a terceros, interinos y de aprendizaje. Las cifras que constatan la desprotección de los trabajadores de la construcción en ambos países, indican que el porcentaje de empleo no registrado de la construcción alcanza al $59,1 \%$ de las empresas de Argentina y al $32,9 \%$ de las empresas de Uruguay (Galín, 1998: 11). Estos empleos precarios, se apartan de alguna de estas características: "ser de tiempo completo, para un sólo e identificable empleador, por tiempo indeterminado, realizado en el domicilio del empleador, generalmente protegido por la legislación laboral y la seguridad social..." (Galín y Novick, 1990:10).

Esta situación se repite en el caso de Rosario donde existen datos contradictorios que dan cuenta de un $30 \%$ de obras no registradas y entre 70 empresas y 120 empresas de la construcción (Según la referencia sea el Registro Nacional de la Construcción, la Cámara Argentina de la Construcción; las empresas que figuran en la Guía de Teléfonos, las Cooperativas de Trabajo registradas en la Municipalidad de Rosario o los registros de la Facultad de Arquitectura). Esta cifra se agrava con la cantidad de obreros que trabajan "en negro" en obras registradas, pues según consta en un informe oficial, durante la visita a 41 empresas de la ciudad, se comprobó que, de un total de cuatrocientos cincuenta y tres trabajadores verificados, estaban en negro trescientos cincuenta, correspondiendo un $30 \%$ a las grandes obras y un $90 \%$ a las pequeñas obras de los contratistas y subcontratistas (Pravisani, 1998:5).
Algo similar ocurre en Brasil, quien presenta un incremento de las muertes por accidentes asociadas a la tercerización de la mano de obra, siendo la construcción civil quien ocupa el primer lugar en el ranking de accidentes. No obstante, cabe resaltar que los registros de siniestralidad son insuficientes pues mientras el INSS sólo computa lo sucedido con unos 24.000 .000 de trabajadores asegurados, el IGBE declara que la población ocupada en el país asciende a las 68.000 .000 personas (Dunningham, 1998:40). También Paraguay posee trabajadores vulnerables en la rama, pues alberga a un $95 \%$ de empleo no registrado dentro de un marco institucional que recientemente comenzó a registrar datos de siniestralidad (Cáceres, 2001).

Igualmente ocurre en el vecino país, donde la tercera parte de los trabajadores posee empresas unipersonales. A esto se suma la subcontratación, y la división del trabajo en la obra, es decir que a los contratistas tradicionales (sanitario, electricistas) se agregan nuevos fraccionamientos de la estructura de hormigón, o de la herrería y la carpintería. (Comisión Directiva de Salud y Seguridad ambiental del PIT/CNT, 2000). Esto se constata en los disímiles registros de la población ocupada, ya que mientras el B.P.S. (Banco de Previsión Social) registra unos 67.000 trabajadores en todo el país comprendidos por la Ley del Aporte Unificado (DL. 14.411/76) (Director de representación de los trabajadores del Banco de Previsión Social, 2000), el ministerio de trabajo señala "si bien están registrados unos 35.000 trabajadores, se calcula que debe ocupar no menos de 55.000 obrero" 
(Inspección del Trabajo del Ministerio de Trabajo y Seguridad Social, 2000:3).

En suma, esta enorme población "en negro" relativiza la cobertura de riesgos del trabajo garantizada a través de la legislación de higiene y seguridad y el sistema de la seguridad social. Por esa razón cabe reflexionar sobre las posibilidades de la gestión preventiva de los riesgos del trabajo, "sobretodo cuando el debate se concentra en el empleo, su volumen y su forma (grado de flexibilidad, precariedad y duración de la jornada) pero ha desaparecido como dilema social el trabajo en sí, su contenido real, la organización y las condiciones de trabajo" (Korinfeld y Alimena, 2001:3).

Asimismo cabe agregar que la modalidad de trabajo en las obras particular se debe a que el oficio impone una relación de producción específica que tiene su propia lógica, flexibilizando las relaciones laborales que cuentan con un fuerte soporte cultural legitimador del comportamiento social de las partes involucradas. En ese ámbito, los papeles, las firmas, lo legal están prácticamente ausentes. La formalidad se suple por la palabra, la cual posee un peso absoluto en el cumplimiento de los roles ocupacionales (Bueno, 1998:128).

En este contexto laboral se inscriben los riesgos del trabajo específicos del sector, que varían con el tipo de construcción (vial, edificio de altura, vivienda de interés social, obra hidráulica, de infraestructura, puente, entre otros). La exposición varía de oficio a oficio, de obra en obra, cada día, incluso cada hora. La ex- posición suele ser intermitente y de corta duración, pero es probable que se repita. Un trabajador puede no solo taparse con los riesgos primarios de su trabajo, sino que también puede exponerse como observador pasivo a los riesgos generados por quienes trabajan en su proximidad. Este modelo de exposición es una consecuencia de tener muchos patrones con trabajo de una duración relativamente corta y de trabajar al lado de otros trabajadores que generan otros riesgos. Los riesgos pueden ser de cuatro clase: químicos, físicos, biológicos y sociales (Hiba, 2000:4).

Varias enfermedades se han asociado a los oficios de la construcción, entre ellas:

- Silicosis, entre los aplicadores de chorros de arena, barreneros, excavadores de túneles y los ocupados en demoliciones.

- Asbestosis (y otras enfermedades causadas por el amianto), de manera principal entre aplicadores de ese mineral.

- Bronquitis, entre soldadores.

- Alergias cutáneas, entre los albañiles y otros que trabajan con cemento.

- Trastornos neurológicos, entre los pintores y otros oficios expuestos a disolventes orgánicos y plomo (Hiba, 2000:4).

No obstante, la forma de prevenir numerosas enfermedades y accidentes en la obra depende de la teoría de gestión preventiva que rige en cada empresa en particular. Por esa razón, a continuación se detallan los posibles abordajes de la misma. 


\section{Gestión de los riesgos del trabajo: ¿una teoría aplicable en la realidad?}

Si bien los estudios de la OIT indican que 5 de cada 20 trabajadores de la construcción sufren lesiones anualmente a causa de accidentes (Instituto Cuesta Duarte/PIT/CNT, 2000), todavía persiste el debate sobre la previsibilidad o la gestión de los riesgos. Por esa razón es necesario reflexionar sobre las visiones sobre "el riesgo" que subyacen en los sindicatos de trabajadores y los gobiernos de cada país. La postura predominante es la "ex post", que posee limitaciones, porque considera a los accidentes y las enfermedades a posteriori, o sea a partir de las consecuencias o secuelas perjudiciales provocadas por el suceso nocivo sobre el trabajador, inquiriendo sobre la culpabilidad del empleador y/o del trabajador ( $\mathrm{Va}$ silachis, 1998:301). La misma se basa en la carencia de mecanismos de gestión de los riesgos y la salud, debido a la falta de tareas preventivas que incluyan la visita regular y sistemática al medio ambiente laboral, tendiente a identificar y controlar los riesgos del trabajo en la obra y las secuelas sobre la calidad de vida en el trabajo y la salud.

Por el contrario, existe una concepción de los accidentes y las enfermedades en la obra, que busca la incorporación de la seguridad y la salud "a priori", desde el proyecto, la realización de los planos de construcción, como en la ejecución de la estructura resistente, la explotación y el mantenimiento de una obra (o la post-obra). En ese sentido, existen experiencias donde se prevé que el especialista en seguridad se siente en un ta- blero y escoja los planos de estructura a fin de proyectar en ellos lo siguiente: 1- planos de instalación de la protección colectiva (redes, barandillas, pasarelas, ubicación de andamios colgantes, ubicación de andamios metálicos apoyados, tendido eléctrico provisional de obra, entre otros), 2- planos de ordenación general de obra (lugares dedicados a los acopios, ubicación de maquinaria fija, caminos de circulación interna para personas, y vehículos, ubicación de almacenes, entre otros); 3- planos de estructura e instalación de: retrete, vestuario, comedor, botiquín, entre otros.; 4- planos de interferencia con líneas de conducciones aéreas o enterradas: eléctrica, alcantarillado, gas, agua potable, oleoducto, entre otros; 5- planos de evacuación interna y externa de accidentados (plano callejero y de carretera) (INSHT, 1991:15).

Esto se logra, integrando la seguridad y la salud al resto de objetivos empresariales como la productividad, la calidad y la protección del medio ambiente. Asimismo, requiere de profesionales de la medicina y la higiene y seguridad laboral que recorran la obra en las diferentes fases constructivas, a fin de conocer y controlar los riesgos físicos (humedad, temperatura, iluminación, vibraciones, ruido), biológicos (contacto con bacterias, hongos, insectos), químicos (polvo, gases, humos), fisiológicos (esfuerzos, posturas) y psicológicos (turnos, conflictos, maltrato, insatisfacción, entre otros) (ISS, 1995: 20), sociales (el cambio de los horarios, la ubicación de los trabajos y las obras de muchos proyectos, le exigen vivir en campamento o viviendas lejos de su hogar, razón por la cual pueden carecer de redes estables y fiables, sumado al 
carácter intermitente del trabajo sujeto a cambios económicos y climáticos por lo que suele sufrir intensa presión para ser más productivo), (Hiba, 2000: 6) tecnológicos, ergonómicos, y de infraestructura (comedor, vestuario, baño, instalación de agua potable).

Otro elemento importante para destacar es la experiencia del Comité BTP de Construcción y Obras Públicas, perteneciente a la Asociación Internacional de la Seguridad Socias (AISS) preocupado por la formación en prevención orientada a: profesionales de la construcción, especialistas de seguridad en la construcción y trabajadores. Asimismo, se incorporó: "las sensibilización de los directivos, de los responsables de proyectos, la formación de los formadores y la formación de seguridad en las pequeñas y medianas empresas" (AISS, 1990).

De los países estudiados, sólo Brasil posee políticas públicas permanentes de difusión de la normativa, de investigación y de capacitación en manos de FUNDACENTRO, que diseña diferentes videos y manuales de seguridad e higiene, acordes al lenguaje y la cultura de profesionales, cuadros medios, capataces y obreros que se distribuyen gratuitamente en todo el país. Por el contrario, los otros dos países del MERCOSUR carecen de políticas que se mantengan en el tiempo, pues tanto Paraguay como Argentina carecen de políticas de investigación de las condiciones de trabajo y salud en el sector $y$ adolece de actividades de capacitación gratuita de los trabajadores y/o profesionales de la construcción.

Cabe destacar que el sindicato argentino carece de tareas de capacitación en higiene, seguridad y salud para todos los trabajadores de obras de diferente porte, pues la Fundación de Capacitación de la Unión Obrera de la Construcción de la República Argentina (U.O.C.R.A.) destina los cursos a las grandes empresas de diferentes puntos del país o a los estudios de arquitectura y/o ingeniería con solvencia económica pues su costo es superior a los $100 \$$ (dólares). Además, ofrece a un costo de $50 \$$ cada Manual Normativo de Seguridad e Higiene de la Construcción producido por esta entidad y destinado a profesionales (según se observa en su lenguaje técnico y en su alto costo).

Desde otra visión preventiva de los riesgos del trabajo se ha señalado la necesidad de:

1. Capacitar a Trabajadores de la salud, pertenecientes a los Centros de Salud o de Atención Primaria de la Salud;

2. Implementar medidas de identificación, validación y divulgación de "tecnología apropiada y limpia" (Tennassee, 1999:289);

Elaborar indicadores regionales de eficiencia, costo/beneficio (a priori y a posteriori), costo/efectividad a causa de los accidentes laborales y las enfermedades producidas en el trabajo para impulsar acciones en: los países (PBI); la gestión empresaria (costos directos e indirectos), la gestión privada de los seguros de accidente y de vida, la gestión del sistema de salud (Osha, 1999:1);

3. Crear un marco normativo regional para las organizaciones públicas, regionales y locales, destinado a la selección de contratistas y subcontratistas y así como a la compra y alquiler 
de equipos de trabajo y elementos de protección personal, en función de sus niveles de seguridad y salud (Osha, 1991:1).

Otro forma de prevenir, ha sido mediante la incorporación de la participación de los trabajadores desde el momento del proyecto, cuando se incluye la prevención de enfermedades y accidentes laborales como lo reitera la OIT en sus documentos anuales. Sin embargo, sólo participan los trabajadores de Uruguay y Brasil, pero lo hacen en la fase de la ejecución de la obra, ya que el proyecto todavía le incumbe exclusivamente a los profesionales de la empresa.

No obstante, la principal cuestión que divide las aguas del debate, proviene de la postura que sólo analiza la ejecución de una obra y aquella que ubica los riesgos en cada fase de la obra desde el proyecto mismo. En ese aspecto, sólo Brasil posee una visión preventiva de los riesgos en las tres etapas, planeamiento y proyecto, obra y post-obra, mediante auditorias técnicas sobre situaciones reales de "predios, instalaciones, máquinas y equipamientos y el proceso industrial de la empresa y su adecuación en relación a requisitos de la legislación vigente. También debe hacerse un estudio del perfil de los trabajadores, abordando cuestiones sobre su nivel de conocimiento en las áreas de seguridad y salud, hábitos y costumbres, escolaridad, entre otras" (Moreira Lima, 2001:3).

Desde este enfoque de gestión de los riesgos en la obra se requiere establecer prioridades en la prevención de modo que lo primero que se debe prever es el control de la fuente del riesgo, luego el control de la trayectoria del riesgo (entre la fuente y el receptor) y por último el control en el receptor (trabajador). "Medidas que de alguna manera evitan o modifican la situación de riesgos en la fuente deben ser consideradas en prioridad. Son medidas que eliminan o reducen la utilización, o la formación de agentes perjudiciales para la salud, por ejemplo, substitución de materiales 0 equipamientos y modificaciones en procesos" (Goelzer, 1999:3). Dentro de dicho marco de prioridades, se incluyen las siguientes medidas de prevención: 1.-control de la fuente del riesgo: substitución de materiales y productos químicos; modificación de procesos y equipamientos; métodos húmedos y manutención de procesos y equipamientos; 2.- control de la trayectoria del riesgo: ventilación industrial (local y general); reducción (enclaustrar, cabinas y distancia) y 3.- control del medio ambiente: layout y organización del trabajo; limpieza, almacenamiento y rotulación adecuada; señales y avisos (áreas restringidas); vigilancia ambiental; 4.- control en el receptor (trabajador): prácticas de trabajo adecuadas; educación, entrenamiento y comunicación de los riesgos; equipo de protección personal; vigilancia de la salud; higiene personal y de la ropa; limitación de la exposición y rotación (Goelzer, 1999:3).

Tomando como marco de referencia esa escala de prioridades cabe señalar que en los casos estudiados de los 4 países, sólo Brasil se encuentra en un estadio continuo de discusión y búsqueda de respuestas de este calibre.

También, a diferencia de los otros países del MERCOSUR, el Ministerio de Trabajo de Brasil realiza periódicamente congresos, seminarios y jornadas de ca- 
pacitación en las diferentes regiones del país, financiando la asistencia masiva de especialistas y expertos nacionales del área como el reciente $I V$ Congresso $\mathrm{Na}$ cional sobre Condições e Meio Ambiente do trabalho na indústria da construção e II Seminário sobre Condições e Meio Ambiente de Trabalho na indústria da construção nos países do Mercosul, realizado en Goiânia durante el mes de abril de 2001. Además solo Brasil posee un Plan Plurianual de Calidad y Productividad que incluye la fiscalización de toda la siniestralidad, el asbesto, el trabajo infantil y el Plan Alimentario en las obras.

\section{Algunas reflexiones finales sobre el desafío para los actores sociales}

Hasta el momento los cambios legislativos de cada país han respondido a necesidades propias " $y$ no responden a una estrategia en que se considere el proceso de integración. En cuanto la unión aduanera es un hecho, en el área de seguridad y salud no se tiene instrumentalizado aquellos mecanismos de consulta que lleven en consideración un avance en común y tampoco formas de cooperación horizontales estables y continuas en el tiempo" (Zuher, 2001:2).
Lamentablemente, los países miembros del MERCOSUR carecen del personal y los recursos gubernamental suficientes para la inspección del trabajo debido al escaso presupuesto y la corrupción ${ }^{11}$, aunque Uruguay suspende el trabajo en las obras a causa de las malas condiciones de los andamios. Sin embargo, existen enormes desigualdades entre los grandes centros urbanos y el interior de los países estudiados, las cuales se acentúan porque la inspección del trabajo está cada vez más limitada a un número escaso de trabajadores cubiertos dentro del sector formal, pues diariamente se incrementa la población de trabajadores "en negro", el empleo informal y los jornaleros dentro del sector formal e informal de la construcción.

Además, Uruguay cuenta con tareas de capacitación gratuita para los trabajadores a cargo de CINTERFOR/OIT, cada vez que aumenta la mortalidad por accidentes de trabajo en la obra. Por el contrario, Brasil posee una entidad dedicada a la investigación, formación e información gratuita y/o a bajo costo en todo el territorio, que de manera ininterrumpida está a cargo de FUNDACENTRO. La misma realiza publicaciones diferentes según los destinatarios: jefe de obra, capataz y albañil.

11 Si bien las empresas saben que para certificar están obligadas a cumplir con las normas, la fiscalización es corrupta. Declaraciones del sindicalista Edson Bernardes del CUT/Brasil (FITCM, 2001). El Programa de televisión de Argentina denominado Telenoche Investiga, reprodujo varios encuentros entre empresarios y sindicalistas de la U.O.C.R.A. que daban cuenta de los sobornos a los que eran sometidos los empresarios de la provincia de Bs. As., para "evitar que tuvieran problemas derivados de la ley de Accidentes de Trabajo" Algunos de ellos se encuentran procesados y otros prófugos (Clarín, 2000). 
Otro aspecto a considerar es la naturaleza del seguro de riesgos del trabajo, pues mientras Argentina posee aseguradoras privadas, Uruguay y Brasil continúan con el seguro público en manos del ente estatal, aunque existen proyectos tendientes a la desmonopolización del mismo. Actualmente ambos sistemas adolecen de tareas preventivas en las obras registradas oficialmente. No obstante el mayor problema deviene del aumento acelerado del empleo informal y del empleo sin cobertura social que están al margen de cualquier tipo de inspección gubernamental.

En cuanto a los empresarios cabe destacar que en Uruguay y en Brasil, in vierten en medidas individuales (elementos de protección personal) y colectivas (redes, vallados perimetrales en huecos y ascensores, señalización, orden y limpieza) de prevención, así como en mejorar las condiciones de bienestar (baños, comedor, vestuario). Por el contrario, la mayoría de los empresarios de Argentina y Paraguay consideran al sistema como un seguro más, donde pagan una alícuota mensual y se desligan de cualquier inversión (incluso eluden contratar un profesional de higiene y seguridad en forma permanente).

Por último, mientras en Uruguay, el Sindicato Unico Nacional de la construcción y Anexos (SUNCA), forma parte de la Comisión de Salud Laboral y Medio Ambiente del PIT/CNT, y ha formado Delegados de Seguridad, el sindicato argen- tino sólo mantiene su preocupación en la asistencia médica tradicional del grupo familiar a través de la obra social del personal de la construcción (Construir Salud). También Brasil posee un organismo destinado al control de la higiene y seguridad en la obra que es el CIPA y destina su personal médico para que discuta con el profesional contratado por los empresarios cuál es lo que se requiere en los exámenes pre-ocupacionales según los riesgos y necesidades de la tarea de cada obrero (profesiogramas).

En cuanto a la fiscalización sindical de las obras en construcción, cabe resaltar que es insuficiente en los 4 países del MERCOSUR, aunque existen diferencias. $\mathrm{Si}$ bien existen algunos sindicatos de Brasil que se mantienen ajenos a la problemática de la seguridad y la salud ${ }^{12}$, también se destacan casos como el del sindicato de Porto Alegre que recorre las obras del sector formal y del informal junto a su personal médico, contando un formulario detallado de la legislación vigente para ser llenado en cada construcción. No obstante se priorizan las obras del sector informal con numerosos trabajadores sin cobertura social. Por el contrario, la fiscalización sindical de las obras en Paraguay y Argentina es escasa y se produce luego de la denuncia de irregularidades extremas 0 a posteriori de un accidente mortal sólo en las obras del sector formal, lo cual reduce ampliamente su alcance.

No obstante, pareciera que existe una incipiente acción conjunta de los gre-

12 Declaraciones de los representantes sindicales de CONTICOM, Josué Ferreira, Paulo Peres Borba y Lucía Costa Maia, (OIT, 1999). 
mios del MERCOSUR dirigidas por la Federación Internacional de los Trabajadores de la Construcción y la Madera (FITCM) /oficina regional para América Latina y El Caribe con sede en Panamá, promoviendo actividades en salud, seguridad e higiene en la obra, como: la capacitación de los dirigentes sindicales en los temas de salud y seguridad; la designación de un comité de salud y seguridad en la obra; la determinación de que los delegados de seguridad destinen un $50 \%$ de su tiempo de trabajo a las cuestiones de salud y seguridad (FITCM: 2001:3).

No obstante, aún se asiste a la invisibilidad de las enfermedades y los accidentes de la construcción en la re-

gión. Sin embargo, la causa de las enfermedades en obra son la precariedad contractual, la flexibilidad, la subcontratación en cadena (que dificulta las tareas de organización y desnuda las responsabilidades) el trabajo autónomo y la presión por la productividad (FITCM, 2001). Esto se suma a la "falta de reconocimientos médicos preocupacionales y periódicos, inspecciones en obra; cláusulas de seguridad y salud entre la comitentes, contratistas y subcontratistas" (Rodríguez, 2001) que coloca a la Argentina y Paraguay en peores condiciones de salud.

En el caso de la construcción, la perspectiva de la salud globalizada precisa de algunas decisiones gubernamentales regionales y nacionales, de investigaciones científicas, empresariales, sindicales y de las organizaciones no gubernamentales en pos de un "trabajo decente", que "no se circunscriba a un trabajo con adecuados niveles de productividad y salarios, sino que requiera que el trabajador esté protegido frente a los riesgos de accidentes, ya que la prevención de estos riesgos constituye una inversión social y es económicamente rentable" (OIT, 1999:18) Esto implica realizar la armonización de las normativas de salud de los trabajadores que vaya acompañada de Acuerdos Multilaterales de la Salud Pública - debido a la creciente informalidad laboral-. Asimismo, requiere de la coordinación de metodologías para evaluar riesgos, ratificar convenios internacionales y armonizar aquellas leyes laborales que regulen las condiciones de trabajo y los subcontratos (Montanaro, 2001:2), asegurar los derechos a la formación e información y participación de los trabajadores en la prevención y la paralización del trabajo inseguro. Si bien en el derecho de la seguridad social cada país tiene un derecho administrativo particular, eso no implica que no se pueda aunar criterios en el reconocimiento de algunos derechos como: las lesiones por esfuerzos repetitivos (L.E.R.), el amianto, el accidente in itinere, entre otros (Carneiro, 2001:2).

Sin embargo, este hecho se vuelve más complejo si consideramos que esta globalización de los mercados e impotencia del Estado se inscriben en un contexto de achicamiento del derecho del trabajo y derrumbe de las mediaciones sociales y políticas tradicionales, que parecen desbordadas por el aumento del desempleo, el empleo informal y el empleo en negro.

Por eso, también cabe reflexionar por el papel de otros actores como las Organizaciones no Gubernamentales (ONG) comprometidas con la salud, el medio ambiente de la comunidad y el trabajo con la opinión pública, porque la 
cuestión de los accidentes es muy escandalosa y sería preciso señalar "aquel producto se hizo con trabajo esclavo y con la muerte de los trabajadores"13. En ese sentido, cabe rescatar la experiencia brasileña de asesoramiento legal y sanitario para las víctimas del amianto, sean o no trabajadores, donde se les otorga asesoramiento legal y sanitario (Rodríguez, 2001:2).

En síntesis, el principal desafío de los países del MERCOSUR radica en el viraje radical del modo de abordaje de los riesgos de trabajo de una obra, que reemplace aquella visión "indemnizatoria del riesgo o compensatoria de los daños" por una nueva concepción de "la gestión de los riesgos" en cada una de las fases de la obra: proyecto, organización y ejecución. Esto implica un cambio en el enfoque de los sectores sociales, sindicales, empresariales, políticos y académicos.

\section{Bibliografía Citada}

AISS (1986), Coloquio para la Prevención de los Riesgos Profesionales en la Construcción, Francia, Informe de un Comité Internacional de la Asociación Internacional de la Seguridad Social (AISS).

AISS (1990), Formación en materia de seguridad en la construcción. Francia, Edición del Comité Internacional de la AISS para la Prevención de Riesgos Profesionales en al construcción.

Assis de Almeida, Jose Gabriel (2000), Impacto da globalizaçao nas relaçoes de trabalho: o caso do Mercosul. Ar- gentina, Ponencia presentada en el VIII Encuentro de Especialistas en el MERCOSUR, II Encuentro Internacional de Derecho de la Integración, organizado por el Centro de Estudios Comunitarios de la Facultad de Derecho de la UNR. Rosario 7 y 8 de septiembre.

ALADI (2000), Indicadores Socio-económicos. Cifras año 1999- Datos Provisionales, Montevideo, Uruguay.

Berlinguer, Giovanni (1993), Conflictos y orientaciones éticas en la relación entre salud y trabajo; Cuadernos de Relaciones Laborales 3, España, Editorial Complutense, pp. 203-225.

B.P.S. (2001), Informe del Empleo Informal y la Seguridad Social en Uruguay. Realizado por el Banco de Previsión Social junto a la Universidad de la República, el CIEDUR y el ICUDU del $\mathrm{PIT/CNT}$. Uruguay.

Bruni, Jorge (1998), Estudio Subregional Sobre los Sistemas de Jubilaciones y Pensiones en los Países del MERCosuR y Chile. Equipo de Representación de los Trabajadores en el Banco de Previsión Social de Uruguay, 3ra Versión, Uruguay, 14 de Septiembre.

Bueno, Carmen (1998) "Los oficios en la construcción de vivienda de la ciudad de México", en: LULLE, THIERRY Lulle (compilador)- El sector de la construcción: actores y estrategias, Centro de Investigaciones sobre Dinámica Social", 2, Serie III, Cuadernos del CIDS, Universidad Externado de Colombia, Colombia. Pp.125-138.

Campinos-Dubernet, Maurice (1984), Quelques reperes sur le BTP, La rationalisation du travail dans le BTP: un 
exemple des limites du taylorisme orthodoxe, Formation Emploi, № 6, avril/juin, La documentation Francaise, Paris, Francia.

Castells, Manuel (1998), La era de la información: economía, sociedad y cultura, Vol. 2, El poder de la identidad. Alianza Editorial, Buenos Aires, Argentina.

CCSCS (2000). Conclusiones del grupo de construcción y la madera. Florianópolis, Brasil, Coordinadora de Centrales Sindicales del Con Sur (CCSCS), Cumbre Sindical del MERCOSUR por el Empleo, el Salario y la Protección Social.

Constituição Federal do Brasil (1988), Brasilia, Brasil.

Comisión Directiva de Higiene y Seguridad de la Asociación de Arquitectos de Uruguay (2000), Entrevista realizada a sus integrantes en el marco de la Beca de Perfeccionamiento de CONICET/Resolución DNo 2133/99, Montevideo, Uruguay.

Comisión Técnica III del Subgrupo 10 del MERCOSUR (1997), Primer Operativo conjunto para el intercambio de experiencias en Inspección del Trabajo -Sector construcción, Montevideo, Uruguay.

Comisión Técnica III del Subgrupo 10 del MERCOSUR (1997), Segundo Operativo conjunto para el intercambio de experiencias en Inspección del Trabajo-Sector construcción, Buenos Aires, Argentina.

Comisión Técnica III del Subgrupo 10 del MERCOSUR (1998), Terceiro Operativo para intercâmbio de experiências em Inspeçao do Trabajo-Setor construçao, Sào Paulo, Brasil.

Comisión Técnica III del Subgrupo 10 del MERCOSUR (1998), Cuarto Operativo conjunto para el intercambio de experiencias en Inspección del Trabajo
-Sector construcción, Asunción, Paraguay.

Conte-Grand Alfredo y Carlos Anibal Rodríguez (1999), Cobertura de los riesgos del trabajo: manual con experiencias actuales y alternativas, OIT, Perú, 1999.

Coriat, Benjamin (1984), Travailler en chantier quelques tendancesde la recherche actualle, Formation Emploi, № 6, avril/juin, La documentation Francaise, Paris.

Declaración Socio-laboral del MERCOSUR (1998), Río de Janeiro, Brasil.

Decreto 911/96, Ministerio de Trabajo y Seguridad Social de la República Argentina, Buenos Aires, Argentina.

Decreto 89/95, Montevideo, Ministerio de Trabajo y Seguridad Social del Uruguay, Montevideo. Año 1995.

Decreto 283/96, Ministerio de Trabajo y Seguridad Social del Uruguay, Montevideo. Año 1996.

Decreto 406/88 (Prevención de Accidentes de Trabajo) título VI, artículo 3, Ministerio de Trabajo y Seguridad Social del Uruguay, Montevideo. Año 1988.

Diario Clarín, jueves 29 de junio de 2000: pp. 10 y 11.

Diario Clarín, 29 de noviembre de 2000. Buenos Aires. <Http:///www.clarin.com. ar /2000-11-29/p-01203.htm

DIESAT. O Futuro do SAT- Seguro sobre Acidente do Trabalho: principios e alternativas, Organizado por el DIESAT e la Plenaria Muncipal de Saúde do Trabalhado de Sào Paulo, Brasil, 05 de julho de 2.000. < Http://www.geocities. com/diesat/sat.htm.>

Dunningham, Andrea; O trabalho sob amenaça da morte; Economia; O Globo, Brasil; Domingo 15 de fevereiro de 1.998: 40-41.

El Gaúcho,11/09/00, Operários se arriscam para nâo perder emprego, Porto Alegre, Brasil. 
Fadel de Vasconcellos, Luiz (2000), Ministerio de Salud de Brasil, Primer Reunión de Vigilancia Epidemiológica Ocupacional de los países Miembros del MERCOSUR y Asociados, organizado por la OPS y la Facultad de Medicina de Rosario, Argentina.

FITCM (2001), La Defensa del Derecho a la Salud de los Trabajadores. Iniciativas Jurídico-Sindicales. En Salud Laboral, Participación Tripartita, Iniciativas Legislativas, Declaraciones Del Coordinador Regional Salud-FITCM Dr. Wellington Carneiro, Seminario Regional de Salud y Seguridad Ocupacional de FITCM para los Países del MERCO. SUR, Buenos Aires, Argentina.

Fleitas, Nestor (2000), Representante del Centro Nacional de Toxicología del Ministerio de Salud de Paraguay, Primer Reunión de Vigilancia Epidemiológica Ocupacional de los países Miembros del MERCOSUR y Asociados, organizado por la OPS y la Facultad de Medicina de Rosario, Argentina.

Frigeri, Graziano (1999), La integración europea, la globalización de la producción y la exportación de los riesgos", IV Congreso del Comité Permanente Europeo de Profesionales de la Seguridad y Salud en el Trabajo; Turín, Italia, 12-13 de marzo de 1999. Traducción al castellano: Manuel Vázquez; Red Salud de los Trabajadores en Latinoamérica y el Caribe de paho/oms. rst-lac@list.mc.duke.edu.

Galín, Pedro (1998), Las regulaciones laborales y su impacto en la competitividad y el empleo, CEFIR, Montevideo, Uruguay.

Galín, Pedro y Novick, Marta (comp.)(1990), La precarización del empleo en la Argentina, CEAL/CLACSO.

Goelzer, Berenice (1999), Substituçao como medida de prevençao e controle de riscos ocupacionais, Biblioteca virtual de la OPS, Washington.
Gro Harlem Brundtland (1999), La enfermedad globalizada, Traducción Elisa CarneIli; en Diario Clarin, mayo, pp.14.

Hiba, Juan Carlos (2000), Condiciones de trabajo, seguridad y salud laborales en el sector de la construcción. OIT, Lima, octubre de 2000.

Hubner, Marlot (2000), Direito Constitucional Do Trabalho Nos Países Do MERCOSUL, Defesa Oral da Tesis de Mestre, Brasil.

Informativo Laboral (2000), № 161, CDE, Asunción del Paraguay, 29.

INSHT (1991), Beguería Latorre, Pedro, Guía práctica para estudios y planes de seguridad e higiene: construcción, Madrid.

Inspección del Trabajo del Ministerio de Trabajo y Seguridad Social de Uruguay (2000), Entrevista realizada al Ingeniero Pierlet en la ciudad de Montevideo, Uruguay, el día 28 de abril.

ISS (1995), Manual para la prevención de accidentes y promoción del trabajo seguro en la industria de la construcción Instituto de la Seguridad Social, Colombia.

Korinfeld, Susana; Marcos Maria Fernanda y Alimena Silvina (2001), El nuevo paradigma económico-productivo y las condiciones de trabajo, ponencia presentada en el 5to Congreso Nacional de Estudios del Trabajo, organizado por la Asociación Argentina de Estudios del Trabajo, Buenos Aires, 1, 2 y 3 de agosto.

Korsunsky, Lionel (2001), Los paradigmas de la globalización y su relación con el concepto de trabajo, ponencia presentada en el 5to Congreso Nacional de Estudios del Trabajo, organizado por la Asociación Argentina de Estudios del Trabajo, Buenos Aires.

La República en la red, Diario La República, Montevideo, 23/01/01- Página 29.

Ley Nacional del Aporte Unificado (DL. 14.411 /76), Montevideo, Uruguay, 1976. 
Ley Nacional No 24.557 de Riesgos del Trabajo (LRT), Buenos Aires, Argentina, 1995.

Ley Nacional 1278/00, Buenos Aires, Argentina, 2000.

Ley Nacional № 213/93, Asunción, Paraguay. 1993.

Litchtenmberg, Leda (2001), Prevençâo das doenças e acidentes graves e fatais na industria da construçao em Porto Alegre, Ponencia presentada en el IV Congresso Nacional Sobre Condições E Meio Ambiente Do Trabalho Na Indústria Da Construção E II Seminário Sobre Condições E Meio Ambiente De Trabalho $\mathrm{Na}$ Indústria $\mathrm{Da}$ Construção Nos Países Do Mercosul, Goiánia, Brasil.

Lobato de Paiva, Mario (2000), Derecho del trabajo mínimo,<http://equipofedraldeltrabajo.desdeinter.net/doctrina/articulos/mario_paiva_derecho_del_ trabajo_minimo.htm.

MERCOSUR/CMC/Dec no 19/97. Acuerdo Multilateral de Seguridad Social del Mercado Común del Sur Montevideo, 15/12/97.

Montanaro, Laura (2001), Integración Regional, Cambios Estructurales y Salud Laboral, La Situación de la Salud en el MERCOSUR, Buenos Aires, Consultor Cinterfor-Oit, En Salud Ocupacional.

Moreira Lima, Jofilo (2001), Gerenciamento de riscos na indústria da construçâo, ponencia presentada en el IV Congreso Nacional sobre condições e meio ambiente do trabalho na indústria da construção e Il seminário sobre condições e meio ambiente de trabalho na indústria da construção nos países do Mercosul, Goiânia, Brasil, 24 al 27 de abril.

MTSS (2001), A segurança e saúde no trabalho da contruçao civil no governo de Uruguai, palestra de Ing. Pierlet da InspeÇao do Trabalho do MTSS en el
IV Congresso Nacional sobre condições e meio ambiente do trabalho na indústria da construção e II seminário sobre condições e meio ambiente de trabalho na indústria da construção nos países do Mercosul, Goiânia, Brasil, 24 al 27 de abril.

Noriega, Mariano (1989), El trabajo, sus riegos y la salud. En: defensa de la salud en el trabajo, México, SITUAM, Pp. 5-12.

Normas Reglamentadora de Seguridad y Salud del Trabajo NR 18, sobre Condiçoes e Meio ambiente de trabalho na indústria da construçao civil, Brasil. D.O.U. 07/05/95.

OIT (1999), Declaraciones de los representantes sindicales de CONTICOM, Josué Ferreira, Paulo Peres Borba y Lucía Costa Maia, ISCOD/CINTERFOR/ OIT. Taller Regional sobre Formación de Formadores en materia de Seguridad y Salud en la construcción, 27 de setiembre y 1 de octubre.Buenos Aires-Argentina.

OPSa (2000), Hispanic Forum on a Safe and Healthy Environment, EUA, Consejo Nacional de Seguridad (NSC), Organización Panamericana de la Salud (OPS), Agencia para la Protección del Medio Ambiente (EPA) y Administración de Seguridad y Salud Ocupacional (OSHA).EEUA.

OPSb (2000), 1er. Taller Nacional de coordinación de Acciones en salud Ocupacional: diagnóstico y estrategias nacionales en salud ocupacional, Uruguay, Ministerio de Salud Pública, MTSS, B.P.S., B.S.E., UDELAR, Cámara de Industrias del Uruguay, PIT/CNT, Sociedad de Medicina del Trabajo, Sindicato Médicos del Uruguay, Montevideo.

OPSc (2000), Programa de Formación en Salud Internacional, Programa de Desarrollo de Recursos Humanos. División de Desarrollo de Sistemas y 
Servicios en Salud, Organización Panamericana de la Salud, Washington D.C. Estados Unidos. ttp: //www.165.158. 1.110/spanish/hsp/ hspitp1.htm

Osha (1999), Repercusión económica de la seguridad y la salud en el trabajo en los Estados miembros de la Unión Europea. URL of this page: http:// agency.osha.eu.int/reports/impact/es lei38.html.

Pania, Marta (2000), Los actores de la transformación territorial con las nuevas reglas de juego de la integración en el MERCOSUR", Presentado en el 50 International Congress of Americanist, Varsovia.

PIT/CNT (2000), Trabajo y salud hacia el tercer milenio. Comisión de Salud Laboral y Medio Ambiente de la Central Sindical de Uruguay (PIT/CNT).

Prat, Graciela (2000), Construcción de viviendas en Uruguay: organización de los procesos de trabajo y calificación de la mano de obra, Documento de Trabajo № 50 , Departamento de sociología, Facultad de Ciencias Sociales/UDELAR, Montevideo.

Pravisani, Atilio (1998), Inspección con resul tados alarmantes en la industria de la construcción local; Suplemento "La Ciudad”, Diario La Capital, Rosario, Domingo 4 de octubre, pp. 5.

Ramírez, Eduardo (2001), Presidente de la Asociación Argentina de Abogados Laborales, Coordinador Asociación Latinoamericana de Abogados Laborales, Declaraciones vertidas en la conferencia dictada en Rosario el día 18 de mayo, Argentina.

Resolución 231/96, Ministerio de Trabajo y Seguridad Social de la República Argentina, Buenos Aires, Argentina. 1996.

Resolución 51/96, Ministerio de Trabajo y Seguridad Social de la República Argentina, Buenos Aires, Argentina. 1996.
Resolución 35/98, Ministerio de Trabajo y Seguridad Social de la República Argentina, Buenos Aires, Argentina. 1998.

Resolución № 319/99, Ministerio de Trabajo y Seguridad Social de la República Argentina, Buenos Aires, Argentina. 1999.

Rodríguez, Carlos Anibal (2001), La seguridad en el sector construcción: el carácter evitable de los accidentes, la prevención y los costos de los accidentes; Ponencia presentada en el Seminario Regional de Salud y Seguridad Ocupacional de FITCM para los Países del MERCOSUR, Buenos AiresArgentina.

Rodríguez, Eduardo (2001), Gerencia de los riesgos, convenio 162 "Uso controlado o prohibición", aspectos ambientales y ocupacionales, Representante del Ministerio de Salud de Argentina, Ponencia presentada en el Seminario Regional de Salud y Seguridad Ocupacional de FITCM para los Países del MERCOSUR, Buenos AiresArgentina.

Serviço de Noticias -n. 36, Correio sindicial do Mercosul, Brasil, 10 de julho de 2000a.

Serviço de Noticias -n.43, Correio sindicial do Mercosul, Brasil, 28 de agosto de 2000b.

Silva, Maria Alejandra (2000), Las condiciones de trabajo que afectan la salud de los obreros de la construcción del MERCOSUR, Informe de Avance, Beca de Perfeccionamiento de CONICET, Rosario-Argentina.

Silva, Maria Alejandra (2000), Precariedad y salud en los obreros de la construcción: ¿saldos de final de milenio?, Revista Medicina y Sociedad, Número 2, Volumen 23:pp 154-169. Buenos Aires-Argentina.

Silva, Maria Alejandra (2001a), A experiència da Argentina é bastante lamentável, 
Entrevista concedida al Jornal "Segurança \& Saúde No Trabalho; Sâo Paulo, Brasil, Ano 5, № 58, junho, pp. 6-7.

Silva, Maria Alejandra (2001b), Globalización y cobertura de riesgos del trabajo: el caso de los accidentes y las enfermedades laborales en el MERCOSUR, XXIII Congreso de la Asociación Latinoamericana de Sociología (ALAS), realizado en la Sede Universidad de San Carlos, Guatemala.

Tennassee, Maritza (1999), Plan Regional de la OPS sobre "Salud de los Trabajadores en la Región de las Américas". División Salud y Ambiente de la OPS. Washington.

Touraine, Alain (1999), ¿Podremos vivir juntos? La discusión del hombre en la Aldea Global. San Pablo, Fondo de Cultura Económica. México.
Vasilachis de Gialdino, Irene (1998), La definición legal de enfermedades y accidentes derivados de las condiciones de trabajo en la reciente legislación internacional. Doctrina Laboral, ERREPAR-DEL- № 151- Marzo- T.XII, Buenos Aires-Argentina.

Zlatkes, Julio (1999), Declaraciones del Representante de la Cámara de Empresas Médico-Laborales de la República Argentina (CEMLARA) en la lista de discusión de la Organización Panamericana de la Salud.

Zuher, Handar (2001), A segurança e saúde no trabalho da contruçao civil e os desafios da globalizaçao, ponencia presentada en el IV Congresso Nacional sobre condições e meio ambiente do trabalho na indústria da construção e II seminário sobre condições e meio ambiente de trabalho na indústria da construção nos países do Mercosul, 24 al 27 de abril Goiânia, Brasil. 